\title{
Role of the biosphere in the mid-Holocene climate of West Africa
}

\author{
Michelle M. Irizarry-Ortiz ${ }^{1}$ \\ Ralph M. Parsons Laboratory, Massachusetts Institute of Technology, Cambridge, Massachusetts, USA \\ Guiling Wang ${ }^{2}$ \\ Goddard Earth Science and Technology Center, NASA Goddard Space Flight Center and University of Maryland, \\ Baltimore County, Greenbelt, Maryland, USA
}

Elfatih A. B. Eltahir

Ralph M. Parsons Laboratory, Massachusetts Institute of Technology, Cambridge, Massachusetts, USA

Received 26 June 2001; revised 2 December 2001; accepted 5 March 2002; published 16 January 2003.

[1] In previous studies, a zonally symmetric, synchronously coupled biosphereatmosphere model (ZonalBAM), which includes explicit representation of ecosystem dynamics, has been developed and validated based on current conditions over the region of West Africa. Here, we use ZonalBAM to study the response of the coupled biosphereatmosphere system to changes in the Earth's orbital forcing during the Middle Holocene (6K yrs BP) and the relative contribution of vegetation feedbacks. Simulations in which vegetation conditions were fixed to the current distribution, show that an orbitally induced increased seasonality in insolation for the Middle Holocene, by itself, results in a $1.1^{\circ}$ northward shift in the location of the southern margin of the Sahara as compared to current solar forcings. When vegetation is allowed to be dynamic, a $2.4^{\circ}$ northward shift is simulated. However, when dynamic vegetation is initialized to palaeovegetation, a $5.1^{\circ}$ northward shift is simulated, bringing results more consistent with palaeoevidence. Based on previous studies on the role of the gradient of moist static energy on the dynamics of large-scale tropical circulations, a mechanism for the enhancement of the summer monsoon circulation has been developed. Our results suggest that multiple equilibria could have coexisted over the region of West Africa during the Middle Holocene. Furthermore, based on previous studies on the current climate over the region, we hypothesize that transitions between the different equilibria could have taken place during the Middle Holocene causing the southern desert margin to migrate between $18.1^{\circ} \mathrm{N}$ and $21.4^{\circ} \mathrm{N}$ and shaping climate variability. INDEX TERMS: 0315 Atmospheric Composition and Structure: Biosphere/ atmosphere interactions; 3322 Meteorology and Atmospheric Dynamics: Land/atmosphere interactions; 3344 Meteorology and Atmospheric Dynamics: Paleoclimatology; 9305 Information Related to Geographic Region: Africa; KEYWORDS: West Africa, Holocene, vegetation dynamics, monsoon, climate change, insolation

Citation: Irizarry-Ortiz, M. M., G. Wang, and E. A. B. Eltahir, Role of the biosphere in the mid-Holocene climate of West Africa, J. Geophys. Res., 108(D2), 4042, doi:10.1029/2001JD000989, 2003.

\section{Introduction}

[2] The Middle Holocene (6K yrs BP) has been widely studied since the effects of insolation on climate can be isolated during that period, while the extent of the ice sheets and global SST conditions [Ruddiman and Mix, 1993] were similar to today's. Changes in the amount of insolation reaching the top of the Earth's atmosphere

\footnotetext{
${ }^{1}$ Now at South Florida Water Management District, West Palm Beach, Florida, USA.

${ }^{2}$ Now at Department of Civil and Environmental Engineering, University of Connecticut, Storrs, Connecticut, USA.

Copyright 2003 by the American Geophysical Union. 0148-0227/03/2001JD000989\$09.00
}

during the Middle Holocene resulting from changes in the Earth's orbital configuration [Berger, 1978a, 1978b] had repercussions on the strength of the West African monsoon. It is of current scientific interest to understand the mechanisms through which these insolation changes impacted the monsoon climate of West Africa during the period resulting in a significant rainfall increase, as has been widely recorded. Palaeontological, geochemical and sedimentological proxy records suggest significantly wetter conditions over the Sahel/Sahara region during the Middle Holocene (6K yrs BP), with the grass coverage expanding as much as $500 \mathrm{~km}$ further north (to $\sim 23^{\circ} \mathrm{N}$ ) and lakes showing significantly wetter conditions to about $30^{\circ} \mathrm{N}$ [Hoelzmann et al., 1998; Jolly et al., 1998a, 1998b] as compared to current conditions. 
Table 1. Summary of Results Based on the Simulated Location of the Southern Desert Margin

\begin{tabular}{cccccc}
\hline $\begin{array}{c}\text { Name of Set } \\
\text { of Simulations }\end{array}$ & $\begin{array}{c}\text { Vegetation } \\
\text { Processes }^{\mathrm{a}}\end{array}$ & $\begin{array}{c}\text { Initial Vegetation } \\
\text { Distribution }\end{array}$ & $\begin{array}{c}\text { Location of the } \\
\text { Southern Desert } \\
\text { Margin for 0 Years BP }\end{array}$ & $\begin{array}{c}\text { Location of the Southern } \\
\text { Desert Margin for 6000 } \\
\text { Years BP }\end{array}$ & $\begin{array}{c}\text { Difference in the } \\
\text { Location of the Southern } \\
\text { Desert Margin }\end{array}$ \\
\hline VSC & Static & Current & $16.3^{\circ} \mathrm{N}$ & $17.4^{\circ} \mathrm{N}$ & $1.1^{\circ}$ \\
VDC & Dynamic & Current & $15.7^{\circ} \mathrm{N}$ & $18.1^{\circ} \mathrm{N}$ & $2.4^{\circ}$ \\
VSM & Static & Mid-Hol. & $20.4^{\circ} \mathrm{N}$ & $21.4^{\circ} \mathrm{N}$ & $1.0^{\circ}$ \\
VDM & Dynamic & Mid-Hol. & $15.4^{\circ} \mathrm{N}$ & $20.5^{\circ} \mathrm{N}$ & $5.1^{\circ}$ \\
\hline
\end{tabular}

${ }^{\mathrm{a}}$ Refers to vegetation conditions between $\sim 5^{\circ} \mathrm{N}$ and $\sim 27^{\circ} \mathrm{N}$. In all simulations, vegetation north of $\sim 27^{\circ} \mathrm{N}$ has been fixed to grassysavannah.

[3] Several studies using general circulation models (GCMs) have found significantly wetter conditions over West Africa during the Middle Holocene. However, the extent of the monsoon penetration has been consistently underestimated. As an example, a series of AGCM simulations based on current and 6K yrs BP forcings have been performed as part of the Palaeoclimate Modeling Intercomparison Project (PMIP) [Harrison et al., 1998]. In these models, the biosphere-atmosphere-ocean interactions have been limited by fixing vegetation characteristics (such as albedo and surface roughness) and the sea surface temperature (SST) to their current conditions. The output of these simulations has been subsequently used to force the BIOME model [Prentice et al., 1992] giving the vegetation distribution in equilibrium with these forcings. Although the PMIP simulations show a northward shift of the rainfall and vegetation belts, none of these models produced a shift in vegetation biomes comparable to observations $(\sim 500 \mathrm{~km})$. Other studies in which the land surface conditions have been fixed to their current values have similarly underestimated the extent of the monsoon penetration [Kutzbach and Guetter, 1986; Yu and Harrison, 1996; Hall and Valdes, 1997; Masson and Joussaume, 1997]. This implies that orbital changes alone are not sufficient to produce the wetter than today conditions suggested by palaeodata. Although the vegetation, soil, surface waters, and ocean feedbacks on climate have been omitted in these studies, these have been identified as possible mechanisms through which orbital forcings could have been enhanced to produce the observed significant rainfall increase. Several attempts to at least partially include these effects have resulted in mixed conclusions due to the difficulty in separating robust climate features and those which are model-dependent.

[4] The role of vegetation in the dynamics of West African monsoons has been demonstrated by Xue and Shukla [1993], and more recently by Zheng and Eltahir [1998]. Reconstructions of the $6 \mathrm{~K}$ yrs BP land surface conditions [Hoelzmann et al., 1998] have been incorporated into simulations of the Middle Holocene by the PMIP [Kutzbach et al., 1996; Broström et al., 1998] in an attempt to bring simulations closer to palaeoclimatic reconstructions. For example, Broström et al. [1998] found a reduction in the discrepancy between the simulated and recorded steppe/desert limit from a range of $5^{\circ}-9^{\circ}$ to a range of $2^{\circ}-5^{\circ}$ in latitude when fixing land-surface conditions based on Hoelzmann et al.'s [1998] map of palaeovegetation and soils, instead of the current distribution. However, incorporating fixed changes to the lake and wetland areas did not improve model results, contrary to Coe and Bonan's [1997] findings.

[5] Several studies by the PMIP have gone further by asynchronously coupling ocean and/or static-vegetation models to AGCMs [Texier et al., 1997; Braconnot et al., 1999; de Noblet-Ducoudré et al., 2000], but still have not been able to fully reproduce the wetter conditions. The importance of synchronously coupling the different components of the climate system together has been stressed by several studies as the key to more accurately reproduce the palaeoclimate [Broström et al., 1998; Hoelzmann et al., 1998; Braconnot et al., 1999]. The reason behind this is that, contrary to asynchronous coupling, synchronous coupling guarantees the use of only one common parameterization for the surface processes and its interactions, resulting in more consistent results [Foley et al., 1998].

[6] We have only found one study, for both current and $6 \mathrm{~K}$ yrs BP forcings, in which the ocean, atmosphere and vegetation have been synchronously coupled [Ganopolski et al., 1998 (PMIP)]. In this study, vegetation dynamics has been found to account for the major precipitation changes in the region. However, the role of the ocean has remained ambiguous, contrary to the significant positive ocean contribution found by Braconnot et al. [1999] and Liu et al. [1999]. Although these results agree with the palaeoclimate, the coarse model resolution of $10^{\circ}$ in latitude by $51^{\circ}$ in longitude does not allow for a detailed analysis of regional dynamics. The most recent effort in this direction has been by Doherty et al. [2000 (PMIP)] with the synchronous coupling of an atmosphere and vegetation model with a resolution of $4.5^{\circ}$ in latitude by $7.5^{\circ}$ in longitude. However, as with other models, the expected greening of the region has not been fully reproduced.

[7] Here, we use a zonally symmetric, synchronously coupled biosphere-atmosphere model (ZonalBAM) as a tool to study the main features of the response of the West African climate to varying precessional forcing and the relative contributions of vegetation dynamics. The basic motivations behind this study are: (1) to understand the mechanisms underlying the expansion of the Sahara desert from the Middle Holocene to its current extent, and (2) to validate the use of a zonally symmetric biosphere-atmosphere model in simulating climate change over the region.

\section{Model Description}

[8] The region of West Africa $\left(\sim 5^{\circ} \mathrm{N}-35^{\circ} \mathrm{N}, \sim 15^{\circ} \mathrm{W}-\right.$ $\left.15^{\circ} \mathrm{E}\right)$ is currently under the influence of both the meridional overturning known as the Hadley circulation, and the monsoon circulation. Since the Atlantic coast is basically parallel to the Equator and due to the physiographic simplicity of the region, the monsoon circulation is mainly a meridional phenomenon. These two meridional circulations together result in a close to zonally symmetric climate over the region south of $\sim 25^{\circ} \mathrm{N}$ which justifies 
Table 2. Parameters Used in Simulations

\begin{tabular}{ccc}
\hline Parameter & 0 Years BP & 6000 Years BP \\
\hline Orbital parameters: $^{\text {a }}$ & & \\
Eccentricity & 0.0167 & 0.0187 \\
Obliquity ( ${ }^{\circ}$ ) & 23.45 & 24.10 \\
Precession ( ${ }^{\circ}$ ) & 102.04 & 0.87 \\
SSTs in the South Atlantic & Current & Current \\
SSTs in the Mediterranean & Current & Current \\
Vegetation north of $\sim 27^{\circ} \mathrm{N}$ & Fixed to grassy- & $\begin{array}{c}\text { Fixed to grassy- } \\
\text { savannah }\end{array}$ \\
\hline
\end{tabular}

${ }^{\mathrm{a}}$ Derived from Berger [1978a, 1978b].

the use of zonally symmetric models. The validity of this assumption, has been tested by Zheng and Eltahir [1998], where they quantitatively showed that the meridional components of both the net water vapor flux and moist static energy in the region are significantly larger than their zonal counterparts.

[9] In previous studies, a zonally symmetric, synchronously coupled biosphere-atmosphere model (ZonalBAM), which includes explicit representation of ecosystem dynamics, has been developed and validated based on current forcings [Wang and Eltahir, 2000a]. It combines a zonally symmetric atmospheric model and a fully dynamic biospheric model through which feedbacks in the system can take place. The model domain covers the whole globe with a uniform resolution in sine of latitude (46 grid points, $\sim 2.5^{\circ}$ near the tropics) representing the zonal average between $15^{\circ} \mathrm{W}$ and $15^{\circ} \mathrm{E}$, and 21 vertical levels. In the original model, the West African coastline is set at $5^{\circ} \mathrm{N}$ with ocean southward and land northward of this location. However, here we also include a representation of the Mediterranean from $\sim 35^{\circ} \mathrm{N}$ to $\sim 40^{\circ} \mathrm{N}$. The timestep is $20 \mathrm{~min}$.

[10] The atmospheric model includes a representation of atmospheric dynamics, a radiation scheme, a convection scheme, a boundary layer scheme and a cloud parameterization scheme [Wang, 2000]. Parameters describing the Earth's orbital configuration for a given time are given as inputs from which the incoming solar radiation is calculated. For the radiation calculation, seasons are defined based on the modern calendar with the vernal equinox fixed at March 21. Consequently, changes in the length of the seasons due to changes in the Earth's orbit are neglected.

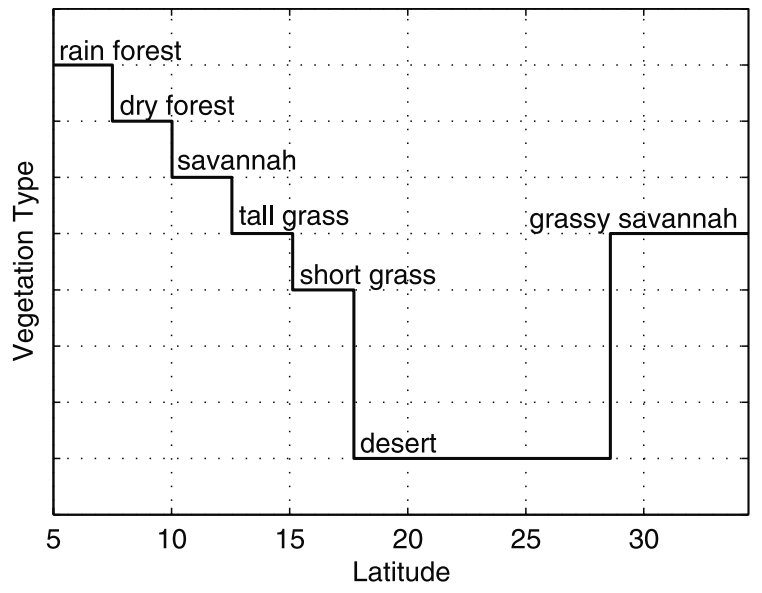

Figure 1. Close-to-observed vegetation distribution.
Table 3. Initial Vegetation Distribution for 0 and 6000 Years BP

\begin{tabular}{ccc}
\hline & \multicolumn{2}{c}{ Vegetation Type $^{\mathrm{a}}$} \\
\cline { 2 - 3 } Latitudes $\left({ }^{\circ}\right)$ & 0 Years BP $^{\mathrm{b}}$ & 6000 Years BP $^{\mathrm{c}}$ \\
\hline $5.0-7.5$ & 1 & 1 \\
$7.5-10.0$ & 2 & 2 \\
$10.0-12.6$ & 4 & 4 \\
$12.6-15.1$ & 5 & 4 \\
$15.1-17.7$ & 6 & 5 \\
$17.7-20.4$ & 8 & 6 \\
$20.4-23.0$ & 8 & 7 \\
$23.0-25.8$ & 8 & 8 \\
$25.8-28.6$ & 8 & 7 \\
$28.6-31.4$ & 9 & 9 \\
$31.4-34.4$ & 9 & 9 \\
\hline
\end{tabular}

${ }^{\mathrm{a}}$ Description of vegetation types: 1-rain forest, 2-dry forest, 3-forestsavannah mosaic, 4-woody savannah, 5-tall grass, 6-short grass, 7semidesert, 8-desert, 9-grassy-savannah.

${ }^{\mathrm{b}}$ Close-to-observed vegetation distribution derived from USGS Global Land over Characterization Data; Gornitz and NASA, 1995; and Foley et al., 1996.

${ }^{\mathrm{c}}$ Vegetation distribution derived from Hoelzmann et al. [1998].

[11] Due to ZonalBAM's regional configuration, it does not take into account large-scale forcings such as those imposed by global SST anomalies. Therefore, it can only be forced with the time series of South-Eastern Atlantic SSTs or with its climatology. Forcing the model with the climatology of regional SSTs (from NCEP optimum interpolation SST analysis [Smith and Reynolds, 1998]), averaged over $15^{\circ} \mathrm{W}$ to $15^{\circ} \mathrm{E}$, has been found to accurately reproduce the current climate [Wang and Eltahir, 2000a]. For the Middle Holocene, the tropical Atlantic SSTs have been found to assert a dominant influence in Sahel rainfall when compared to ENSO anomalies [Otto-Bliesner, 1999], which is encouraging when using ZonalBAM in simulating conditions during the period.

[12] Being a zonally symmetric model, ZonalBAM is computationally more efficient than 3-D models, but on the other hand its applicability is limited. Due to its zonal symmetry, the model does not provide for the simulation of asymmetrical climate features such as localized ocean upwelling/downwelling, and midlatitude high- and lowpressure systems. The latter results from baroclinic instability, and represents a significant transport mechanism in middle latitudes, especially during winter. For this reason, in an effort to reduce model biases, the climatology of fluxes

Table 4. Total Leaf Area Index for Evergreen, Deciduous and Lower Canopy Plant Functional Types (pfts) Comprising Each Vegetation Type in ZonalBAM

\begin{tabular}{ccccccccc}
\hline & \multicolumn{8}{c}{ LAI for Vegetation Type } \\
\cline { 2 - 9 } pft $^{\mathrm{b}}$ & 1 & 2 & 4 & 5 & 6 & 7 & 8 & 9 \\
\hline Upper canopy & & & & & & & & \\
Evergreen & 4.0 & 1.0 & 0.125 & 0.125 & 0.025 & 0.05 & 0.0005 & 0.15 \\
Deciduous & 2.0 & 5.0 & 1.0 & 0.125 & 0.025 & 0.05 & 0.0005 & 0.15 \\
Lower canopy & 0.5 & 0.5 & 4.2 & 4.2 & 1.1 & 0.3 & 0.026 & 2.75 \\
\hline
\end{tabular}

${ }^{a}$ Evergreen pfts include tropical broadleaf evergreen tree, temperate conifer evergreen tree, warm-temperate broadleaf evergreen tree, boreal conifer evergreen tree. Deciduous pfts include tropical broadleaf droughtdeciduous tree, temperate broadleaf cold-deciduous tree, boreal broadleaf cold-deciduous tree, boreal conifer cold-deciduous tree. Lower canopy pfts include evergreen shrub, cold-deciduous shrub, warm (c4) grass, cool (c3) grass.

${ }^{\mathrm{b}}$ See Table 3 for a description. 


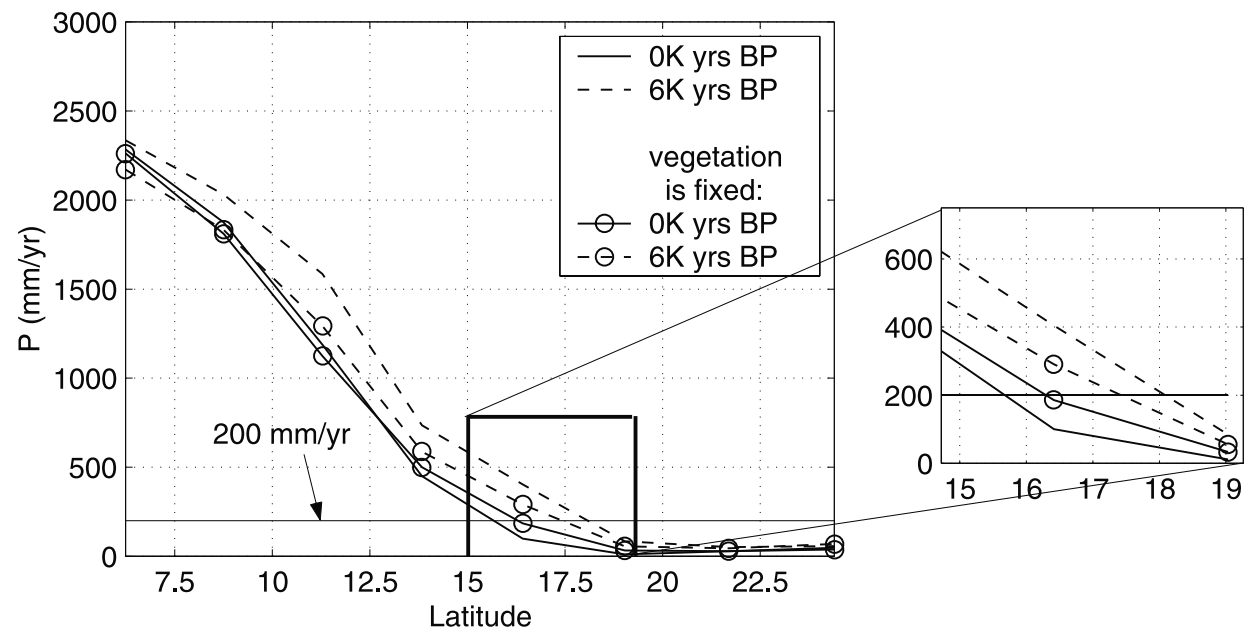

Figure 2. Distribution of annual precipitation $(\mathrm{mm} / \mathrm{yr})$ at equilibrium for simulations with dynamic vegetation initialized to the current distribution (solid and dashed lines). Lines with circles represent simulations in which static vegetation conditions were fixed at the current distribution.

and temperatures beyond the tropics (averaged between $15^{\circ} \mathrm{W}$ and $15^{\circ} \mathrm{E}$ ) can be specified as boundary conditions and fixed throughout a simulation, as has been done in simulating the current climate [Wang and Eltahir, 2000a; Wang, 2000]. However, since these fluxes are not quantitatively known for the Middle Holocene and since conditions are expected to be quite different from the current, we chose to let the model calculate these fluxes and fix any vegetation north of $\sim 27^{\circ} \mathrm{N}$ as grassy-savannah. Results of sensitivity analyses on this issue indicate that this choice does not make a significant difference in the simulated climate.

[13] The biospheric model uses the Integrated BIosphere Simulator (IBIS), developed by Foley et al. [1996]. IBIS takes the meteorological forcings provided by the atmospheric model as inputs, returns to the atmospheric model outputs that describe surface properties and fluxes, and updates the biospheric state including the vegetation structure based on the carbon budget for each plant functional type (pft). Initial vegetation conditions are specified over land, and can be fixed within a certain region or could be let to dynamically interact with the atmosphere until an equilibrium is established.

\section{Experiments}

[14] The successful simulation of past climate change is a critical component in the process of validating a climate model. It would give us some insight onto the way in which interactions between the different components of the climate system (i.e. atmosphere, biosphere, ocean, surface waters) take place. The understanding gained would ultimately allow for model improvement. For this purpose, we attempt to validate the utility of our climate model, ZonalBAM, in reproducing climate change over the region of West Africa by using the Middle Holocene as a basis for comparison with current forcings. Our main objective is to understand the mechanisms responsible for a greener Sahara during the Middle Holocene.

[15] According to Eltahir and Gong [1996], the gradient of moist static energy between the land and the ocean affects the strength of the monsoon circulation. Therefore, changes in any of the two components will ultimately result in precipitation changes over land. Here, our objective is limited to understanding how changes to the energy balance over land could have resulted in wetter conditions during the Middle Holocene. With the objective of assessing the relative contributions of orbitally induced changes in radiation, vegetation dynamics, and the sensitivity to initial vegetation conditions, four different sets of experiments based on current and $6 \mathrm{~K}$ yrs BP orbital forcings were designed. Results of these simulations are tabulated in Table 1 in terms of the simulated location of the southern desert margin, hereafter defined as the location of $200 \mathrm{~mm} / \mathrm{yr}$ annual precipitation.

[16] The sets of simulations VSC and VSM, in which vegetation is fixed to the current and Mid-Holocene distribution respectively, were performed with the intention of isolating the response of the climate system to orbitally induced insolation changes at the top-of-the-atmosphere. In the sets of simulations VDC and VDM, vegetation is initialized to either the current or Mid-Holocene distribution and allowed to dynamically interact with climate until an equilibrium is established. The particular objective is to assess whether the Mid-Holocene climate system can evolve into a wetter equilibrium through vegetation dynamics enhancing the orbital signal alone (simulations VDC), or if the initial vegetation conditions (simulations VDM) play a significant role in determining the equilibrium attained by the system.

[17] These simulations are described in more detail in the following sections and the main forcings used are tabulated in Table 2.

\subsection{Orbitally Induced Climate Change (Simulations VSC)}

[18] An initial set of simulations (VSC) were performed with the purpose of isolating the effect of the different orbital forcings for 0 and $6 \mathrm{~K}$ yrs BP. In these simulations, we fixed the vegetation to the close-to-observed distribution (Figure 1; and Table 3, column 2), which consists of rain 

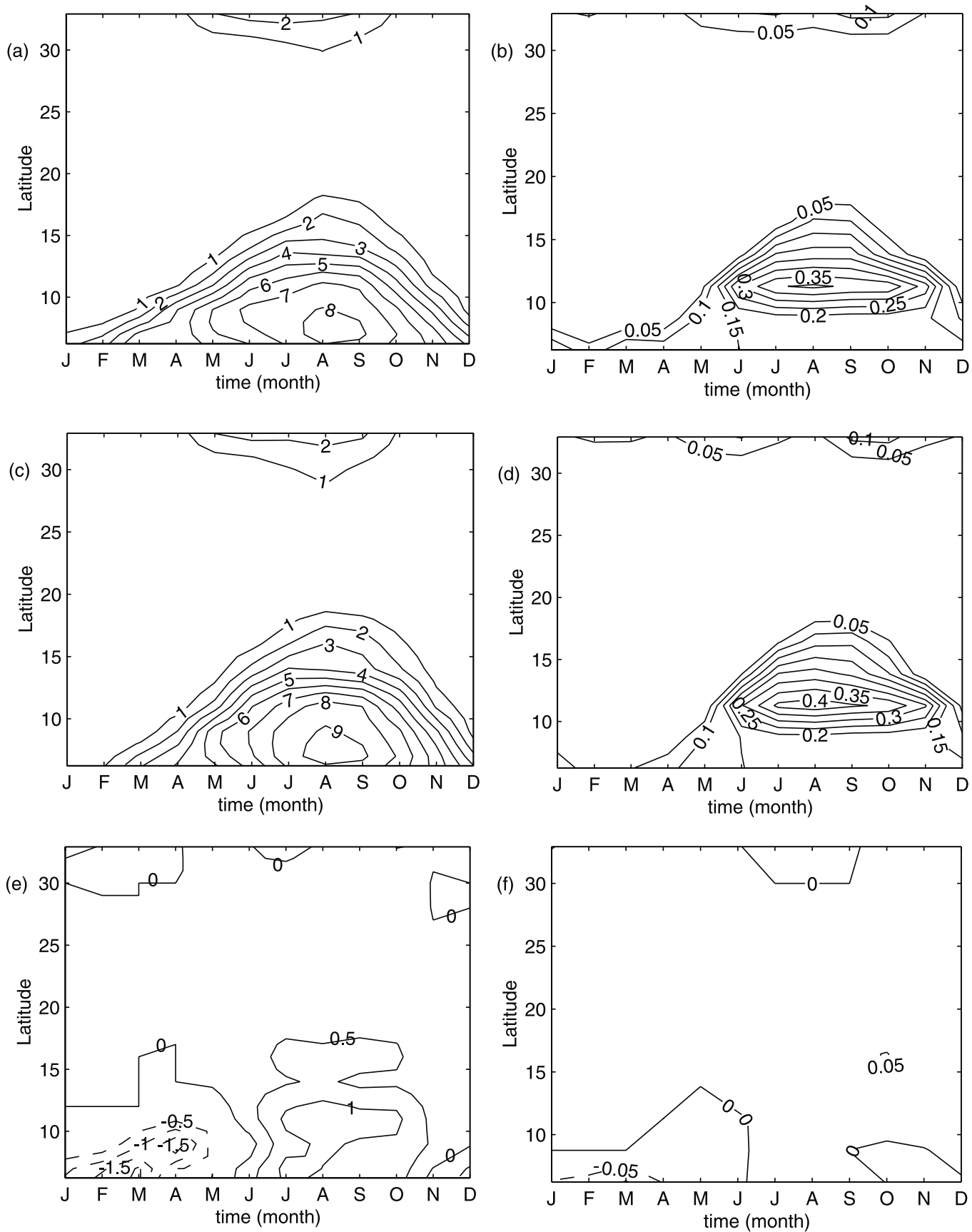

Figure 3. Results for simulations with vegetation fixed (static) to the current distribution (simulations VSC): (a) Seasonal cycle of rainfall (mm/day) and (b) net primary productivity $\left(\mathrm{kgC} / \mathrm{m}^{2} / \mathrm{mo}\right.$ ) for $0 \mathrm{~K}$ yrs $\mathrm{BP}$; (c) Seasonal cycle of rainfall and (d) net primary productivity for $6 \mathrm{~K}$ yrs BP; (e) Difference of Figures $3 c$ and 3a; (f) Difference of Figures 3d and 3b. See color version of this figure at back of this issue.

forest in the Coast of Guinea $\left(\sim 5^{\circ} \mathrm{N}\right)$, gradually becoming sparser northward. The specific characteristics associated to each vegetation type, such as the combination of plant functional types (pfts) and their corresponding fractional coverage and leaf area index (LAI), were also kept constant among simulations (Table 4).

[19] Results show that the $6 \mathrm{~K}$ yrs BP forcing produces a slight rainfall increase (Figure 2, solid-circled and dashedcircled lines) over the region from $\sim 9^{\circ} \mathrm{N}$ to $\sim 19^{\circ} \mathrm{N}$ due to a simulated local strengthening of the monsoon during sum- mer (Figure 3c). However, in these simulations, vegetation is not allowed to respond to this rainfall increase, and its distribution is inconsistent with the Middle Holocene. Consequently, the static vegetation basically serves to anchor the system to the current climate so that the expected monsoon expansion during the Middle Holocene is not well simulated.

[20] The most dramatic difference in land cover between $6 \mathrm{~K}$ yrs BP and present is recorded for the region of the Sahel-Sahara between $\sim 16.5^{\circ} \mathrm{N}$ and $\sim 23.5^{\circ} \mathrm{N}$, with the 

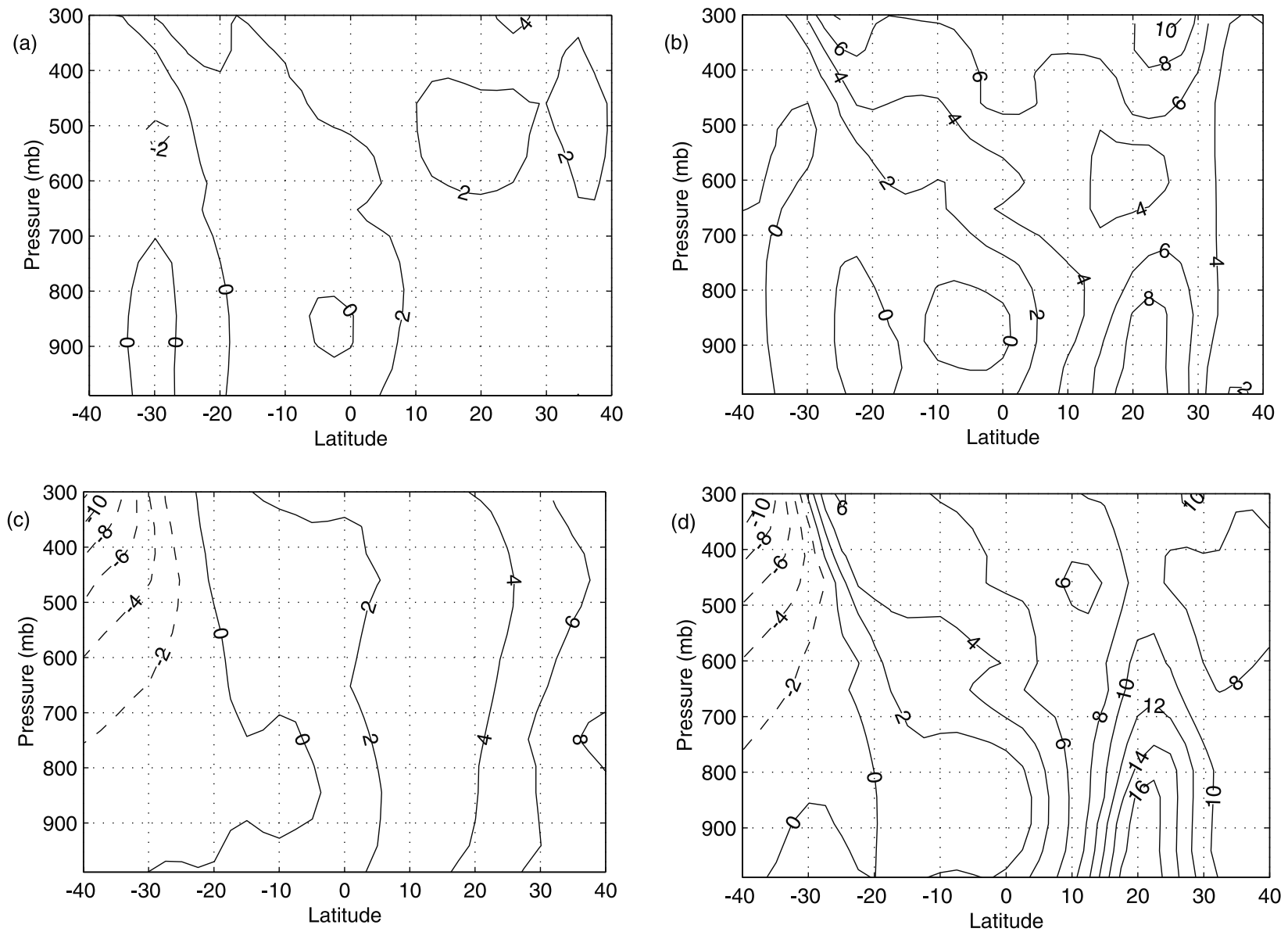

Figure 4. Difference $\left(6 \mathrm{~K}-0 \mathrm{~K}\right.$ yrs BP) in the equivalent potential temperature $\left({ }^{\circ} \mathrm{K}\right)$, which is proportional to the moist static energy, for simulations (a) VSC, (b) VDC, (c) VSM, and (d) VDM.

current land surface being desert and the $6 \mathrm{~K}$ yrs BP land being covered by grass/savannah. Results for this critical region show that the orbitally induced increase in top-ofthe-atmosphere radiation for the Middle Holocene summer is capable of increasing the net radiation received at the land surface by only $\sim 11 \mathrm{~W} / \mathrm{m}^{2}$. This limited response in the net radiation results from the fixed surface albedo over the region, which is inconsistent with conditions during the Middle Holocene and acts by reflecting a significant amount of radiation back to space. This small increase in the net surface radiation in turn acts to increase the latent and sensible heat fluxes over land. With conditions over the ocean being anchored by the specified fixed SST climatology, the increased fluxes of latent and sensible heat fed into the land's boundary layer produce a slightly steeper gradient of moist static energy (Figure 4a). As a consequence, the summer monsoon slightly strengthens producing a northward migration of the southern desert margin by $\sim 1.1^{\circ}$ (from $16.3^{\circ} \mathrm{N}$ to $17.4^{\circ} \mathrm{N}$, Table 1).

\subsection{Impact of Vegetation Dynamics (Simulations VDC)}

[21] In order to allow for a more complete response of the climate system to the different orbital forcings, vegetation in the region from $\sim 5^{\circ} \mathrm{N}$ to $\sim 27^{\circ} \mathrm{N}$, was initialized to the closeto-observed distribution and allowed to dynamically interact with the climate until an equilibrium is established (simu- lations VDC). It is found that the $6 \mathrm{~K}$ yrs BP forcing produces a higher rainfall over the whole domain (Figure 2, solid and dashed lines), specially during summer (Figure 5c). However, the rainfall increase near the desert margin is not enough to allow for a significant northward expansion of vegetation.

[22] In simulations VSC, where we isolated the response of the West African climate to insolation changes by fixing vegetation to its current distribution, we found a slight rainfall increase for the simulation using $6 \mathrm{~K}$ yrs BP orbital forcings. When vegetation is allowed to be dynamic, it responds to this increase in rainfall by becoming greener (Figure 5f), which again feeds back and adds to the strength of the monsoon circulation.

[23] Since a lower surface albedo is associated with a greener vegetation distribution, we find a significant increase in the net surface radiation for the simulation based on $6 \mathrm{~K}$ yrs $\mathrm{BP}$ forcings. The orbitally induced increase in top-of-the-atmosphere radiation for the Middle Holocene is now capable of significantly increasing (by $\sim 46 \mathrm{~W} / \mathrm{m}^{2}$ ) the net radiation reaching the land surface. The increased net radiation reaching the surface allows for a significant increase in the total latent and sensible heat fluxes, as expected. The increase in the energy fluxes fed into the land's boundary layer results in an even steeper gradient of moist static energy with respect to the ocean (Figure 4b) and hence in a healthier monsoon. As a result, the southern 

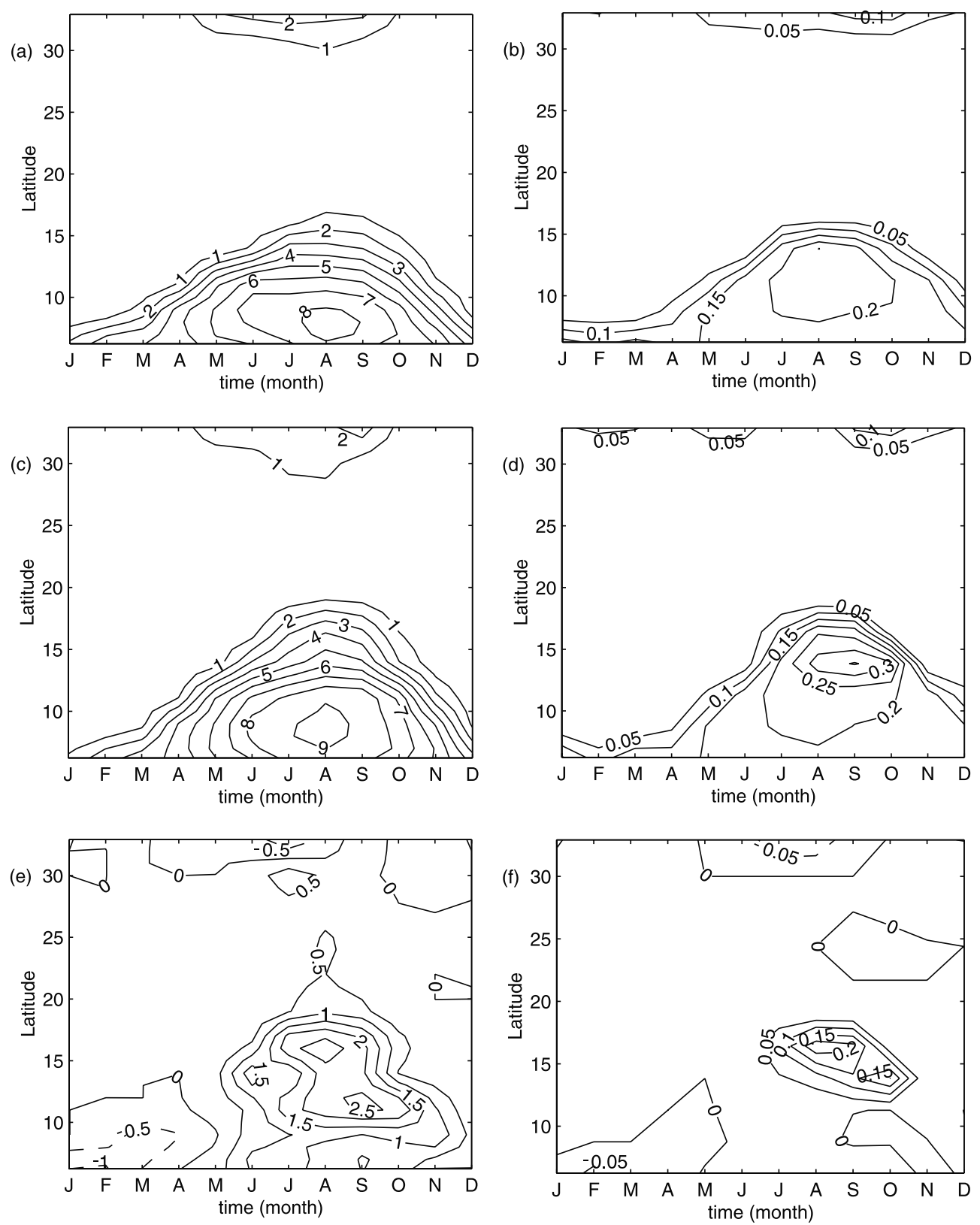

Figure 5. Results for simulations with vegetation initialized (dynamic) to the current distribution (simulations VDC): (a) Seasonal cycle of rainfall (mm/day) and (b) net primary productivity $\left(\mathrm{kgC} / \mathrm{m}^{2} /\right.$ mo) for $0 \mathrm{~K}$ yrs BP; (c) Seasonal cycle of rainfall and (d) net primary productivity for 6K yrs BP; (e) Difference of Figures 5c and 5a; (f) Difference of Figures 5d and 5b. See color version of this figure at back of this issue.

desert border migrates northward by $\sim 2.4^{\circ}$ (from $15.7^{\circ} \mathrm{N}$ to $18.1^{\circ} \mathrm{N}$, Table 1 ) as compared to $\sim 1.1^{\circ}$ when vegetation is not allowed to be dynamic.

\subsection{Impact of Changes in Initial Vegetation Conditions (Simulations VSM and VDM)}

[24] Previous studies have demonstrated the importance of incorporating Mid-Holocene vegetation conditions in order to bring simulations closer to palaeoclimatic reconstructions. Based on the information derived from Hoelzmann et al.'s [1998] map of palaeovegetation, we determined the extent of the vegetation belts during the Middle Holocene. Fixing these vegetation conditions (Table 3, column 3; Table 4; Figure $6 \mathrm{a}$ ) in the region from $\sim 5^{\circ} \mathrm{N}$ to $\sim 27^{\circ} \mathrm{N}$ in a simulation based on current orbital forcings (simulations VSM), we find significantly wetter conditions than currently observed, especially north of $\sim 8.8^{\circ} \mathrm{N}$ (Figures $7 \mathrm{a}, 7 \mathrm{~b}$, and 8 ). However, when vegetation in this region is allowed to dynamically respond to climate (simulations VDM), we find that these cannot be sustained under current forcings (Figures 7a, 7b, 9a, and 9b). The model reaches an equilibrium very similar to the currently observed climate, the same as when it was forced with the close-to-observed vegetation distribution (Figures 8 and 10). 

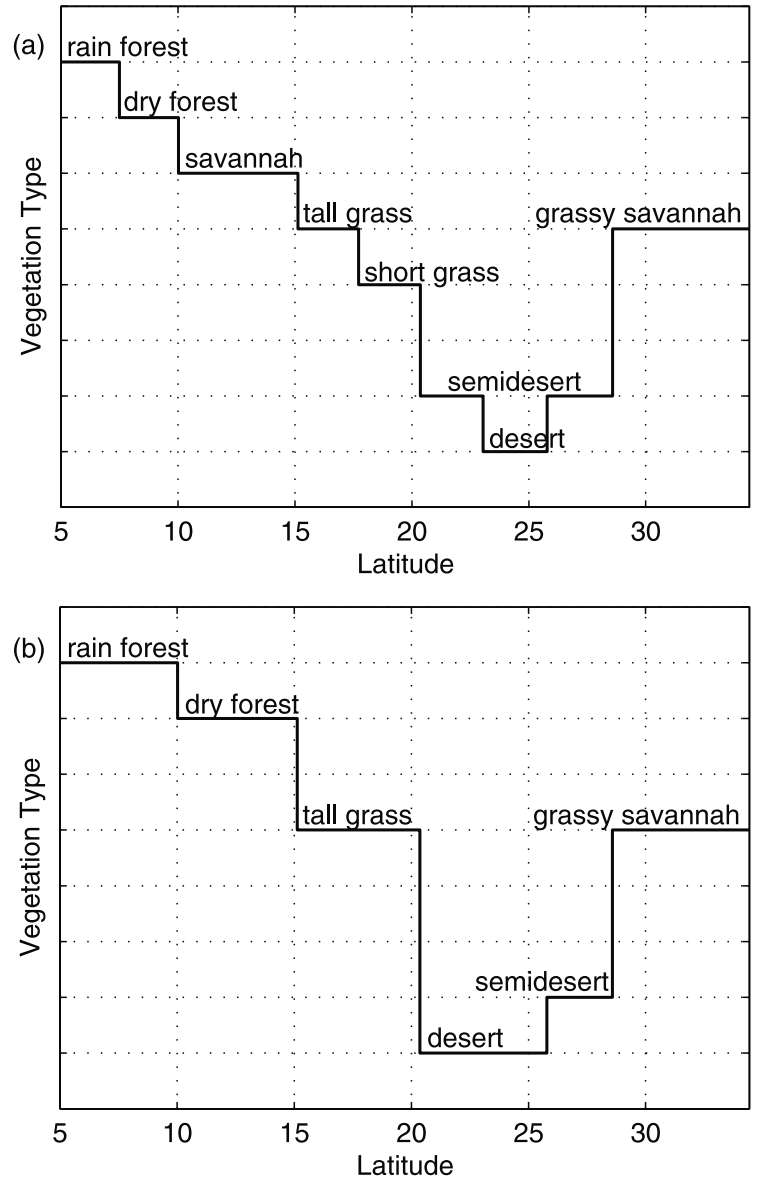

Figure 6. (a) Initial and (b) equilibrium vegetation distribution for $6 \mathrm{~K}$ yrs BP for vegetation initialized based on Hoelzmann et al.'s [1998] map of palaeovegetation.

[25] Fixing this more realistic vegetation distribution for the Middle Holocene (simulations VSM), we find a wetter equilibrium for the period as compared to the currently observed conditions (Figures $7 \mathrm{c}$ and $7 \mathrm{~d}$ ). When vegetation is allowed to be dynamic (simulations VDM), the equilibrium climate (Figure 9c and 9d) does not depart much from that of the simulation with fixed vegetation. This suggests that these vegetation conditions can indeed survive under Mid-Holocene forcings.

[26] In these simulations (VDM), we found significantly wetter conditions for the Mid-Holocene, although slightly drier than expected (Figures 6b, 8 and 9c). Water demanding vegetation types such as forest and grassland expand northward by $\sim 500 \mathrm{~km}$ to $\sim 20.5^{\circ} \mathrm{N}$ as compared to conditions simulated for the current climate $\left(\sim 15.4^{\circ} \mathrm{N}\right.$, defined as location of $200 \mathrm{~mm} / \mathrm{yr}$ precipitation). The equilibrium vegetation classes for the simulation based on 6K yrs BP orbital forcings differ from the initial distribution in that savannah was replaced by dry forest. The same behavior was observed when simulating the current climate starting from the closeto-observed vegetation distribution. This can be attributed to the fact that the model does not represent the external disturbances (e.g. grazing, fires) which are believed necessary for the maintenance of savannah vegetation in this model [Wang, 2000]. Although we were successful in sim- ulating a northward expansion of $\sim 500 \mathrm{~km}$ in vegetation, our model was not able to sustain the initially specified sparse vegetation at $\sim 23^{\circ} \mathrm{N}$ from observations. This mismatch with reconstructions of palaeoprecipitation is probably due to the lack of other significant feedbacks in the system, such as soil texture, surface waters, and changes in ocean conditions.

[27] One would expect a system with multiple equilibria to be characterized by its sensitivity to initial conditions. The different results we obtained when using different initial vegetation conditions corresponding to the current (simulations VDC) and Mid-Holocene distributions (simulations VDM) suggest the possibility that multiple equilibria could have coexisted during the Middle Holocene. These results disagree with studies by several groups [Claussen and Gayler, 1997; Brovkin et al., 1998; Claussen et al., 1999] which have identified only a single green equilibrium for the West African region during the Middle Holocene. Brovkin et al. [1998], using a simple conceptual model, found only a stable green equilibrium from about 10 to $6 \mathrm{~K}$ yrs BP. They also found a dry stable equilibrium, and an intermediate, but unstable equilibrium appearing since the Middle Holocene (6K yrs BP). This multiple equilibria state starting at $6 \mathrm{~K}$ yrs BP is probably what is being reflected in our results. Several studies suggest that conditions during the Middle Holocene were more complex than previously thought with smaller-scale fluctuations reflecting possible different causes than the broad trends attributable to orbital forcings [Street-Perrott and Perrott, 1993]. As an example, Gasse and Van Campo [1994] found several dry spells on the reconstructed lake levels of the Termite $\left(16^{\circ} 05^{\prime} \mathrm{N}\right.$, $\left.11^{\circ} 15^{\prime} \mathrm{E}\right)$ and Bougdouma $\left(13^{\circ} 19^{\prime} \mathrm{N}, 11^{\circ} 40^{\prime} \mathrm{E}\right)$ sites. In their study the possible mechanisms reflecting these fluctuations have been identified as a competition between the vegetation-related decrease in surface albedo and the increased evapotranspiration from the expanded lakes and vegetation.

[28] For the current climate, Wang and Eltahir [2000b, 2000c, 2000d] found the existence of multiple climate equilibria, and demonstrated how climate transitions between different equilibria shape the currently observed low-frequency rainfall variability over the region. Based on their findings, we hypothesize that similar transitions could have taken place during the Middle Holocene causing the southern desert margin to migrate between $18.1^{\circ} \mathrm{N}$ (simulations VDC) and $21.4^{\circ} \mathrm{N}$ (simulations VDM). This could act as a mechanism for natural oscillation in the MidHolocene climate. We hypothesize that West African conditions during the Middle Holocene were in general wetter than today with possible fluctutations superimposed on these mean conditions. Small perturbations either in the land surface conditions or in the external forcings (e.g. SSTs) could have driven the system from the wetter equilibrium to the drier one for relatively short intervals of time (decade to century). We realize however, that the possible existence of multiple equilibria for the period needs to be corroborated by the introduction of oceanic variability and other feedbacks into the climate system.

\section{A Mechanism for Monsoon Enhancement During the Middle Holocene}

[29] In this section, we present a more detailed comparison of the simulated climate for 0 and $6 \mathrm{~K}$ yrs BP for the 

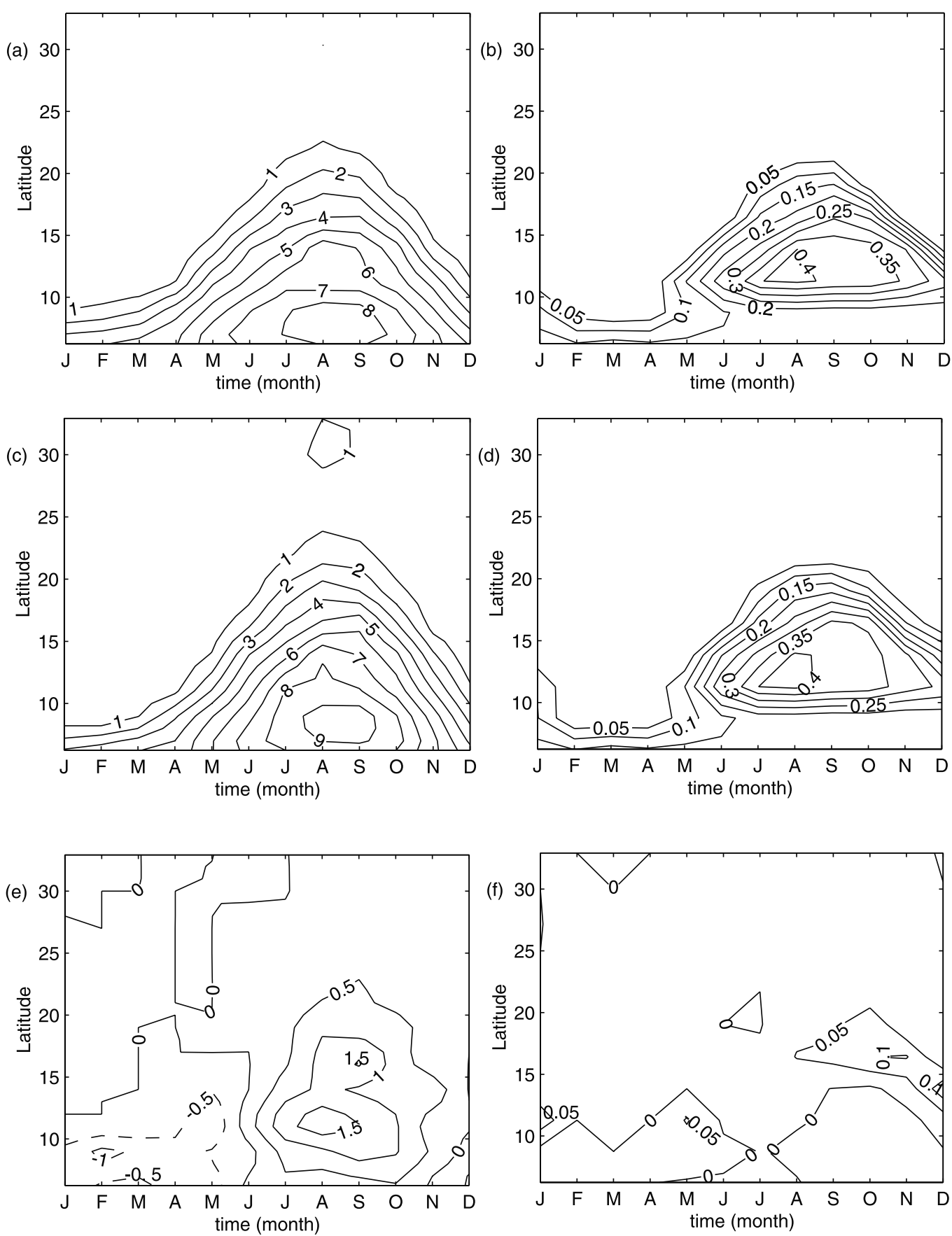

Figure 7. Results for simulations with vegetation fixed (static) to the Mid-Holocene distribution (simulations VSM): (a) Seasonal cycle of rainfall (mm/day) and (b) net primary productivity $\left(\mathrm{kgC} / \mathrm{m}^{2} /\right.$ mo) for $0 \mathrm{~K}$ yrs BP; (c) Seasonal cycle of rainfall and (d) net primary productivity for 6K yrs BP; (e) Difference of Figures 7c and 7a; (f) Difference of Figures 7d and 7b. See color version of this figure at back of this issue.

set of simulations in which vegetation is initialized based on Hoelzmann et al.'s [1998] map of palaeovegetation and vegetation is subsequently allowed to be dynamic (simulations VDM). Significantly wetter/greener conditions were simulated in the case based on $6 \mathrm{~K}$ yrs $\mathrm{BP}$ forcings as a result of a significant enhancement of the West African summer monsoon, although these were slightly drier than expected from palaeoclimatic reconstructions
(Figures 6a, 8, and 9c). Here, our intention is to present in a coherent manner, the mechanisms responsible for the enhancement of the West African summer monsoon during the Middle Holocene. A comparison of the main changes between current and Mid-Holocene summer (JAS) conditions simulated for the region between $16.5^{\circ} \mathrm{N}$ and $23.5^{\circ} \mathrm{N}$ (currently part of the Sahara desert) is shown in Table 5 . 


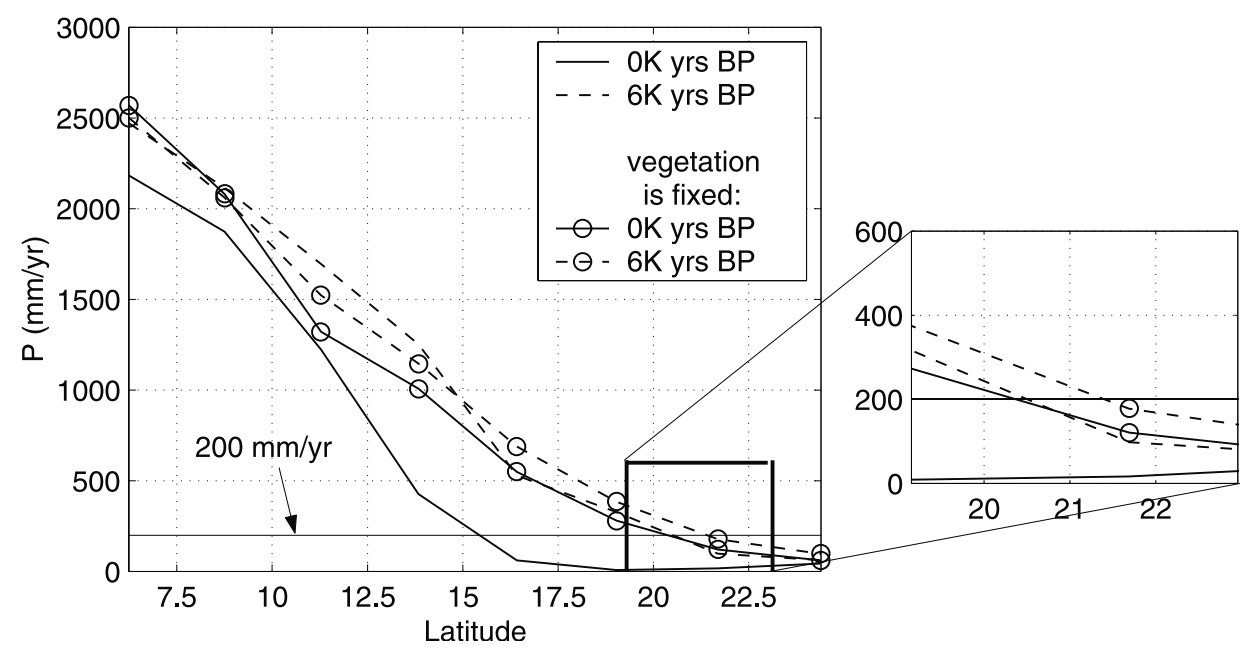

Figure 8. Distribution of annual precipitation $(\mathrm{mm} / \mathrm{yr})$ at equilibrium for simulations with dynamic vegetation initialized according to Hoelzmann et al.'s [1998] map of palaeovegetation (solid and dashed lines). Lines with circles represent simulations in which static vegetation conditions were fixed according to Hoelzmann et al. [1998].

[30] The mechanisms through which the monsoon circulation was enhanced during the Middle Holocene can be explained starting from radiative considerations and are summarized in Figure 11. During the Middle Holocene, perihelion (the time when the Earth is located closest to the Sun) occurred closer to the northern summer and the tilt of the Earth's rotational axis was larger than at present $\left(24.10^{\circ}\right.$ versus $23.45^{\circ}$ ). These changes resulted in an insolation anomaly of about $+6 \%\left(\sim 25 \mathrm{~W} / \mathrm{m}^{2}\right)$ at the top of the atmosphere during the Northern Hemisphere summer. Conversely, they resulted in decreased insolation during the Northern Hemisphere winter. As a consequence of the increased summer insolation over West Africa, the monsoon circulation was enhanced during the season. However, the increased summer insolation alone has proven insufficient to fully reproduce the wetter conditions expected over West Africa during the Middle Holocene, suggesting the need for the inclusion of feedbacks into the system.

[31] The simulated seasonal cycle of net radiation shows significantly higher values during the Middle Holocene than at present (Figure 12 and Table 5). However, the difference is much larger than the $25 \mathrm{~W} / \mathrm{m}^{2}$ expected for the top of the atmosphere during summer suggesting an enhancement of the insolation anomaly. Our modeling results provide some insight into the way in which the biosphere-atmosphere feedback contributes to this enhancement and consequently to the wetter conditions during the period. For this purpose, we recall the hypothesis developed by Emanuel et al. [1994], Eltahir [1996], and Eltahir and Gong [1996] on the role of the gradient of moist static energy between the land and the ocean in regulating the dynamics of large-scale atmospheric tropical circulations (i.e. monsoons). In addition, we base our discussion on the hypothesis developed by Eltahir [1998] for relating land surface conditions and subsequent rainfall processes.

[32] With else being equal, the increased solar radiation at the top of the Earth's atmosphere during the Mid-Holocene summer, results in a slight increase of the net radiation received at the land surface. Based on energy balance considerations, increases in the net radiation at the land surface have to be balanced roughly by corresponding increases in the total energy fluxes (latent and sensible heat fluxes) into the land's boundary layer. With conditions over the ocean being fixed by the specified current SST climatology, the resulting increase in energy fed into the land's boundary layer steepens the gradient of moist static energy between the land and the ocean (Figure 4d). It has been shown by Eltahir and Gong [1996] that a steeper gradient of moist static energy results in a stronger monsoon circulation (Figure 13). Consequently, the initial increase in the summer net radiation over land that resulted from changes in the Earth's orbital configuration during the Middle Holocene, provides an initial mechanism for the enhancement of the summer monsoon circulation over West Africa. The enhanced monsoon circulation simulated for the Middle Holocene results in significant moisture convergence $(P-$ $\left.E_{t}\right)$ as compared to current conditions. As a result, a positive precipitation anomaly is generated over land (Figure 9e) producing moister soil conditions and a greener vegetation distribution.

[33] The initial and equilibrium vegetation distributions for both forcings are shown in Figures 6a, 6b, and 10. The equilibrium vegetation types obtained for the Middle Holocene are significantly greener than for the present. Water demanding vegetation such as forest and grassland shows a significant northward expansion to $\sim 20.5^{\circ} \mathrm{N}$ as a result of a higher water availability, especially during summer/early fall, as compared to present conditions. The greener vegetation distribution and moister soil conditions simulated for the Middle Holocene, result in a significant difference in the way in which the biosphere-atmosphere interactions take place. As shown in Figure 11, the expanded vegetation and moister soil conditions exert a strong influence in the energy balance at the land surface through two mechanisms: (1) decreased Bowen ratio, and (2) decreased surface albedo. It will be shown that both mechanisms result in increased net surface radiation during the Middle Holocene, consistent with Eltahir's [1998] theory. 

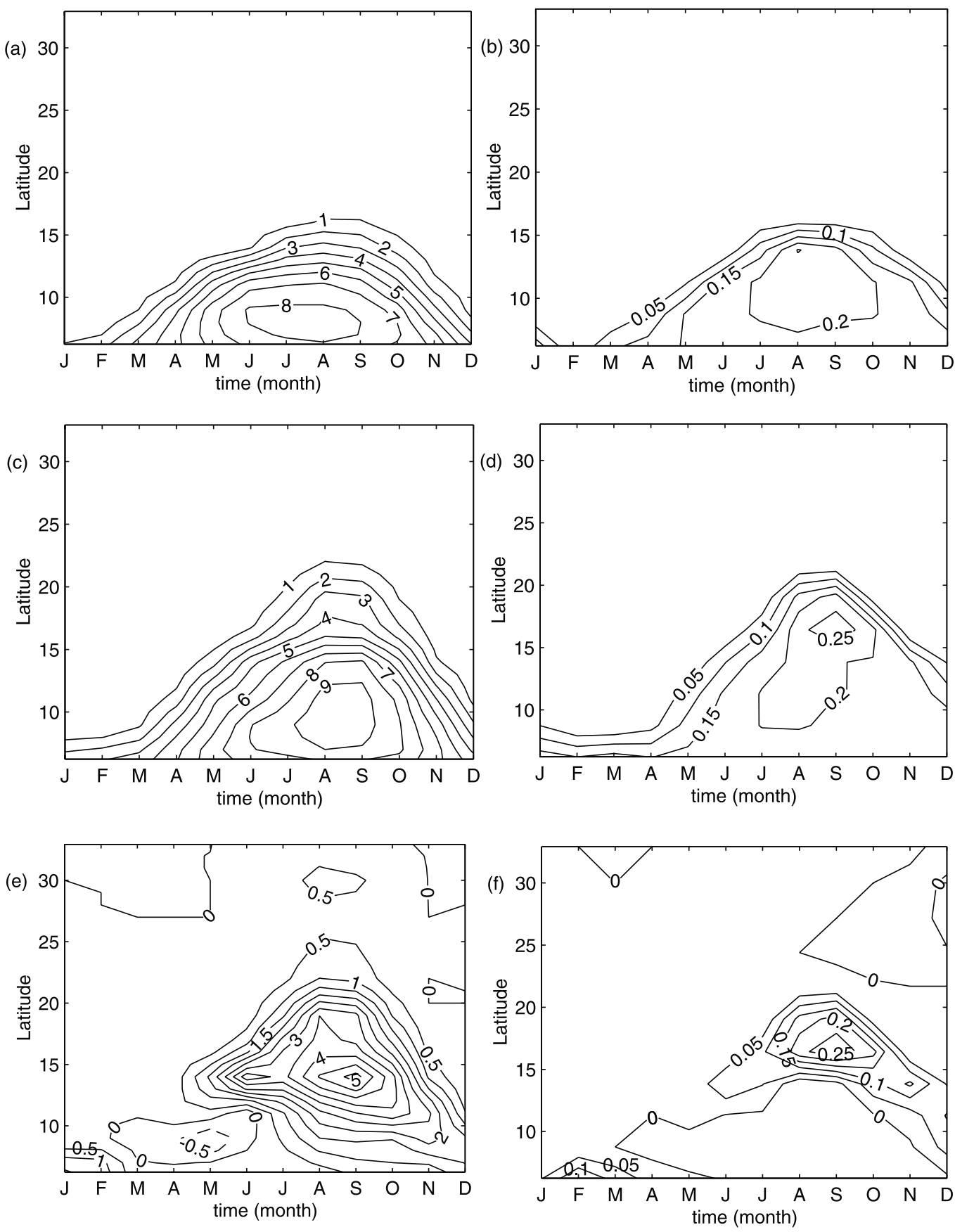

Figure 9. Results for simulations with vegetation initialized (dynamic) to the Mid-Holocene distribution (simulations VDM): (a) Seasonal cycle of rainfall ( $\mathrm{mm} /$ day) and (b) net primary productivity $\left(\mathrm{kgC} / \mathrm{m}^{2} / \mathrm{mo}\right)$ for $0 \mathrm{~K}$ yrs BP; (c) Seasonal cycle of rainfall and (d) net primary productivity for $6 \mathrm{~K}$ yrs BP; (e) Difference of Figures 9c and 9a; (f) Difference of Figures 9d and 9b. See color version of this figure at back of this issue.

[34] Due to the positive precipitation anomaly simulated for the Middle Holocene summer, soil conditions are significantly moister. Since the plant's stomatal resistance to transpiration is inversely proportional to the available soil moisture content, the moister conditions simulated for the Middle Holocene result in decreased Bowen ratio (mechanism 1 above). Therefore, in the competition between latent and sensible heating for the available energy at the surface, the fraction contributing to evapotranspiration is significantly larger for the Middle Holocene, which results in: (a) a significantly more humid boundary layer, and (b) cooler surface temperature in the region with expanded vegetative cover $\left(15^{\circ} \mathrm{N}-20^{\circ} \mathrm{N}\right)$. Since water vapor is the most important greenhouse gas, the more humid boundary layer simulated for the Middle Holocene (result a above) favors a significantly increased downward longwave radiation. Although a 


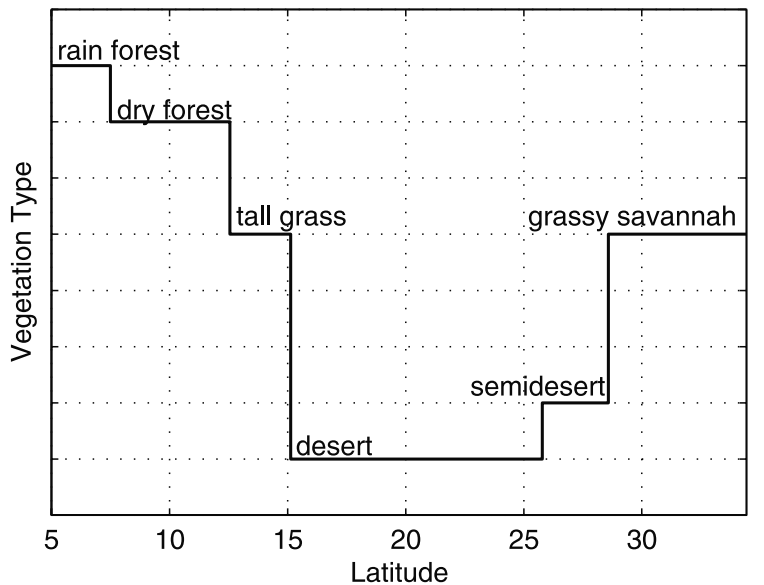

Figure 10. Equilibrium vegetation distribution for $0 \mathrm{~K}$ yrs BP for vegetation initialized based on Hoelzmann et al.'s [1998] map of palaeovegetation.

region of localized cooling is simulated between $15^{\circ} \mathrm{N}-$ $20^{\circ} \mathrm{N}$ as a result of increased evapotranspiration from the expanded vegetation (result $\mathrm{b}$ above), we find an overall small warming of our region of interest $\left(16.5^{\circ} \mathrm{N}-23.5^{\circ} \mathrm{N}\right.$, currently part of the Sahara desert). Consistent with this overall small warming of the surface, the upward longwave radiation increases slightly. The net effect of changes in both longwave components is an increase of the net terrestrial radiation at the land surface (Table 5).

[35] The decreased surface albedo (mechanism 2 above) resulting from the simulated greening/wetting of the region
Table 5. Average Value of Key Variables Simulated for Current and Mid-Holocene Summer (JAS) Conditions in the Region Between $16.5^{\circ} \mathrm{N}$ and $23.5^{\circ} \mathrm{N}$ (Simulations VDM)

\begin{tabular}{cccc}
\hline Variable & 0 Years BP & 6000 Years BP & $\begin{array}{c}\text { Difference (6000 Years } \\
\text { BP to 0 Years BP) }\end{array}$ \\
\hline$B_{o}$ & 4.9 & 0.8 & -4.1 \\
$W_{\text {soil,veg }}$ & 0.01 & 0.16 & 0.15 \\
$G\left(\mathrm{~W} / \mathrm{m}^{2}\right)$ & 118.7 & 106.6 & -12.1 \\
$S H F\left(\mathrm{~W} / \mathrm{m}^{2}\right)$ & 36.1 & 49.8 & 13.7 \\
$L H F\left(\mathrm{~W} / \mathrm{m}^{2}\right)$ & 7.4 & 66.8 & 59.4 \\
$E_{t}\left(\mathrm{~mm} / \mathrm{day}^{2}\right.$ & 0.3 & 2.4 & 2.1 \\
$R_{t, \text { down }}\left(\mathrm{W} / \mathrm{m}^{2}\right)$ & 361.5 & 391.3 & 29.8 \\
$R_{t, \text { up }}\left(\mathrm{W} / \mathrm{m}^{2}\right)$ & 486.9 & 497.4 & 10.5 \\
$R_{t, \text { net }}\left(\mathrm{W} / \mathrm{m}^{2}\right)$ & -125.4 & -106.1 & 19.3 \\
surface albedo & 0.40 & 0.32 & -0.08 \\
$R_{s, \text { net }}\left(\mathrm{W} / \mathrm{m}^{2}\right)$ & 284.7 & 323.0 & 38.3 \\
$R_{\text {net }}\left(\mathrm{W} / \mathrm{m}^{2}\right)$ & 159.3 & 216.9 & 57.6 \\
$P(\mathrm{~mm} / \mathrm{day})$ & 0.2 & 2.2 & 2.0 \\
\hline$B_{o}$ & & &
\end{tabular}

$B_{o}=$ Bowen ratio, $W_{\text {soil } \text { veg. }}=$ soil moisture content available to vegetation $=\mathrm{f}($ soil moisture and rooting profile),$G=$ ground heat flux, $S H F=$ sensible heat flux, $L H F=$ latent heat flux, $E_{t}=$ evapotranspiration, $R_{t, \text { down }}=$ downward longwave radiation, $R_{t, u p}=$ upward longwave radiation, $R_{t, \text { net }}=$ net terrestrial radiation, $R_{s, \text { net }}=$ net solar radiation, $R_{\text {net }}=$ net radiation, $P=$ precipitation.

currently occupied by the Sahara, results in increased net solar radiation at the land surface. At the same time, the increased reflectivity associated with the increased cloudiness simulated over the region, acts to reduce the amount of net solar radiation reaching the land surface. Our results show that the net solar radiation at the land surface increases significantly, suggesting that the impact of surface albedo out-competes the cloud effect.

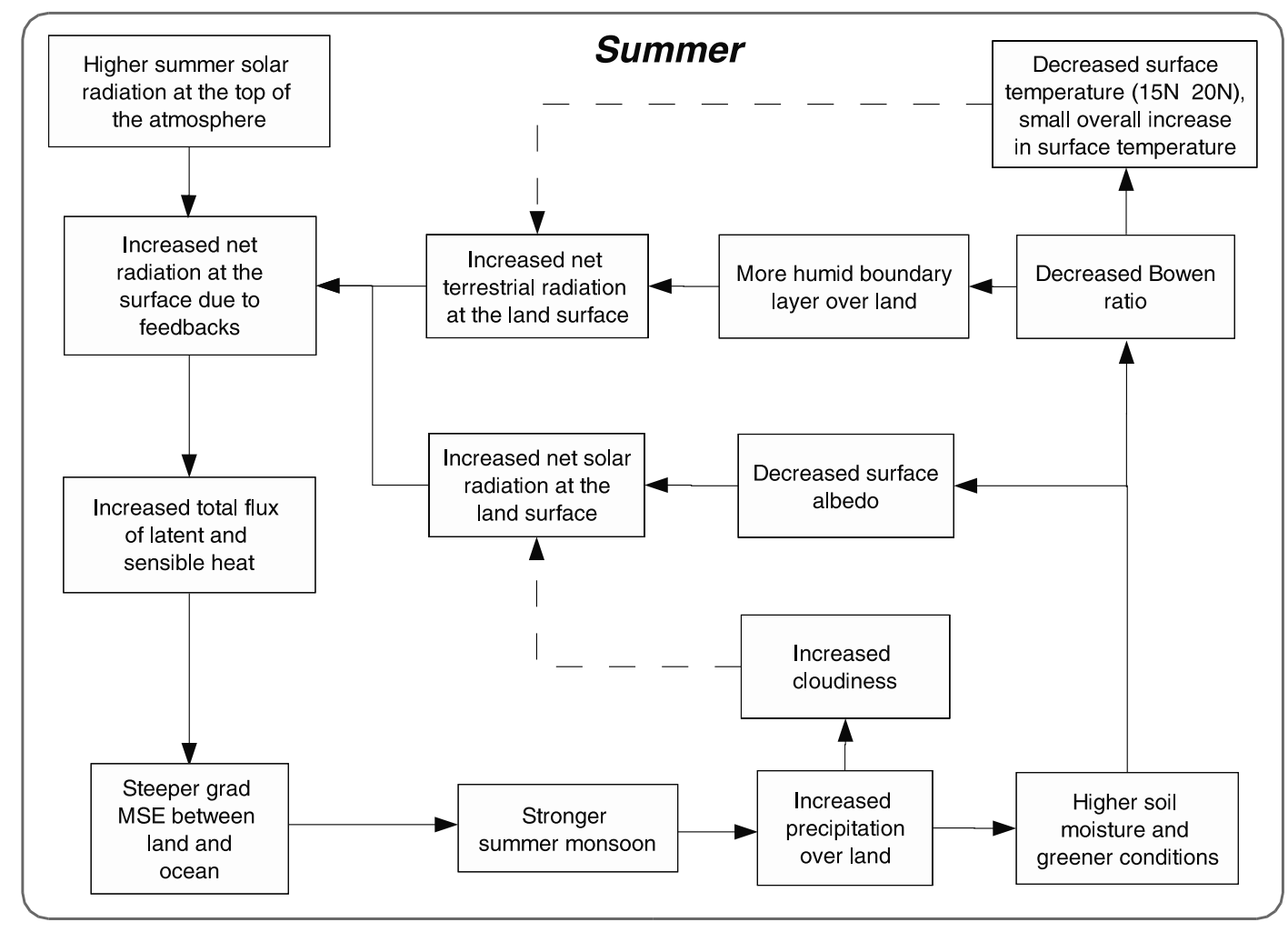

Figure 11. Summary of positive (solid lines) and negative (dashed lines) feedback mechanisms resulting in an enhanced summer monsoon circulation during the Middle Holocene. 

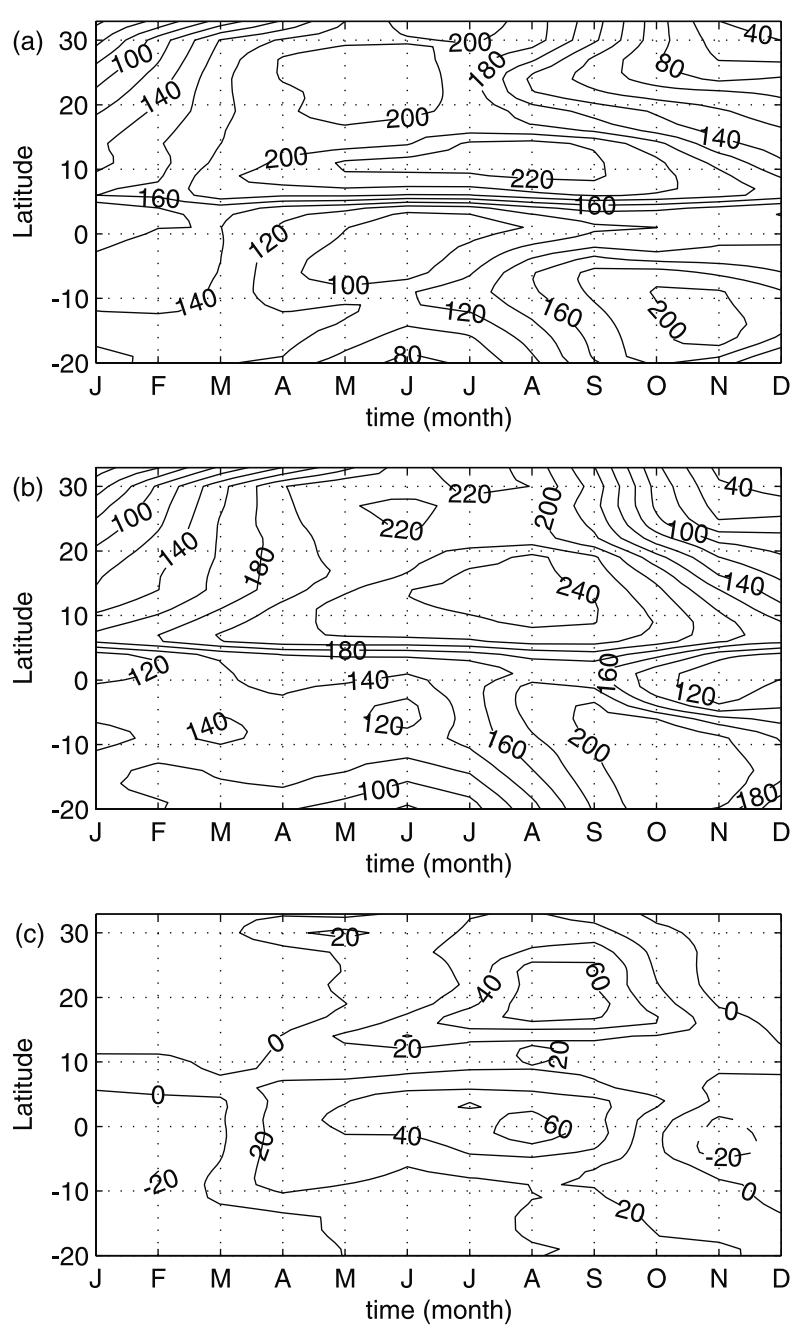

Figure 12. Seasonal cycle of net radiation $\left(\mathrm{W} / \mathrm{m}^{2}\right)$ for (a) $0 \mathrm{~K}$ yrs BP, (b) $6 \mathrm{~K}$ yrs BP, and (c) difference of Figures $12 \mathrm{~b}$ and $12 \mathrm{a}$, for vegetation initialized based on Hoelzmann et al.'s [1998] map of palaeovegetation.

[36] As a result of the increased net terrestrial and net solar radiations received at the land surface, there is an increase of the net surface radiation. The increased net radiation at the land surface is again balanced by corresponding increases in the total energy fluxes (mostly in the form of latent heat) fed into the land's boundary layer. With conditions over the ocean being fixed by the specified SST climatology, an even steeper gradient of moist static energy between the land and the ocean (Figure 4d) is produced. As a consequence, the summer monsoon circulation is further enhanced until an equilibrium is established (Figure 11) in which a significantly stronger monsoon (Figure 13) can be sustained under $6 \mathrm{~K}$ yrs BP orbital forcings.

\section{Summary and Conclusions}

[37] With the purpose of understanding the mechanisms responsible for a greener Sahara during the Middle Holocene, we invoked the theory developed by Eltahir [1996], and Eltahir and Gong [1996] which suggests that the strength of the monsoon circulation is affected by the gradient of moist static energy between the land and the ocean. The relative contribution of orbitally induced changes in insolation and vegetation dynamics to the energy balance at the land surface, which determine the amount of moist static energy fed into the land's boundary layer, were analyzed by performing four different sets of experiments based on current and $6 \mathrm{~K}$ yrs BP orbital forcings.

[38] Simulations in which vegetation conditions were fixed to the current distribution, show that an orbitally induced increased seasonality in insolation for the Middle Holocene, by itself, results in a $1.1^{\circ}$ northward shift in the location of the southern margin of the Sahara as compared to current forcings. This limited response is due to the fact that the fixed land surface conditions limit the increase in the net radiation at the surface. Therefore, only small increases in the latent and sensible heat fluxes, which feed the land's boundary layer with moist static energy, were simulated, resulting in a limited enhancement of the monsoon. When vegetation is allowed to be dynamic, it responds to the simulated increase in rainfall resulting in greener conditions. As a result of this feedback, more moist
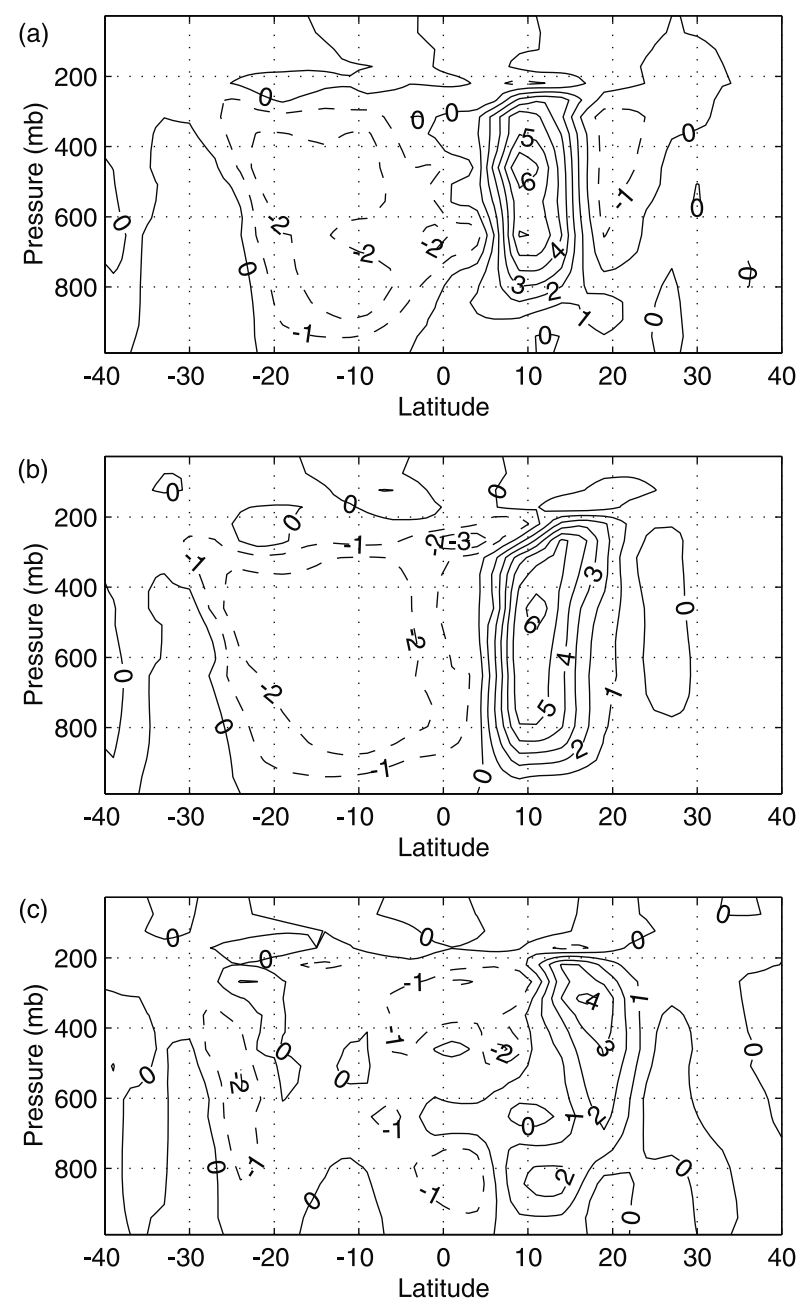

Figure 13. Vertical wind ( $\mathrm{mm} / \mathrm{s})$ at equilibrium for (a) $0 \mathrm{~K}$ yrs BP, (b) $6 \mathrm{~K}$ yrs BP, and (c) difference of Figures 13b and 13a, for vegetation initialized based on Hoelzmann et al.'s [1998] map of palaeovegetation. 
static energy is fed into the land's boundary layer strengthening the monsoon even further. Consequently, the southern desert margin shifts northward by $2.4^{\circ}$ in this case. However, the system by itself was not able to fully reach the greener equilibrium expected from observations.

[39] Motivated by this limited response, simulations in which vegetation was initialized to palaeovegetation were performed and the question of whether these could be sustained under current and Mid-Holocene orbital forcings was posed. We found that this vegetation distribution cannot not be sustained under current forcings. However, it can be sustained under $6 \mathrm{~K}$ yrs $\mathrm{BP}$ forcings resulting in a $5.1^{\circ}$ northward shift in the southern desert margin. Although we were successful in simulating a northward expansion of $\sim 500 \mathrm{~km}$ in vegetation, our model was not able to sustain the initially specified sparse vegetation at $\sim 23^{\circ} \mathrm{N}$ from observations. This mismatch with reconstructions of palaeoprecipitation is probably due to the lack of other significant feedbacks in the system. Despite of this mismatch, it is remarkable that a simple zonally symmetric model was able to capture the retreat of the Sahara during the Middle Holocene.

[40] The different results obtained when initializing the model with different vegetation distributions (simulations VDC and VDM) for the Middle Holocene suggest the possibility that multiple equilibria could have coexisted during the period. Even though other studies have identified only a single green equilibrium during the Middle Holocene, lake evidence support the possibility that the climate during the period was not as stable as previously thought. Although the main mechanisms responsible for the enhancement of the West African summer monsoon during the Middle Holocene and the possibility of multiple equilibria for the period have been discussed from the point of view of the biosphere-atmosphere system, we are aware that the incorporation of additional feedbacks could introduce more complication. For example, the incorporation of other feedbacks such as changes in soil type, surface waters, and ocean dynamics have been identified as possible additional mechanisms that could have resulted in significantly wetter conditions during the Mid-Holocene. In addition, it is important to incorporate into this analysis a temporal dimension in which seasonal and interannual changes are also taken into account.

[41] Acknowledgments. This research has been supported by the National Aeronautics and Space Administration (NASA) under agreement NAG5-5201, NAG5-7525, and NAG5-8617, and by the National Science Foundation (NSF) under agreement ATM 9807068. The views, opinions, and/or findings contained in this paper are those of the authors and should not be construed as an official NASA, or NSF, position, policy, or decision, unless so designated by other documentation.

\section{References}

Berger, A. L., A simple algorithm to compute long term variations of daily or monthly insolation. Tech. Rep. 18, Inst. d'Astron. et de Geophys. Georges Lemaitre, Univ. Catholique de Louvain, Louvain-la-Neuve, Belgium, 1978a.

Berger, A. L., Long-term variations of daily insolation and Quaternary climatic changes, J. Atmos. Sci., 35(12), 2362-2367, 1978b.

Braconnot, P., S. Joussaume, O. Marti, and N. de Noblet, Synergistic feedbacks from ocean and vegetation on the African monsoon response to mid-Holocene insolation, Geophys. Res. Lett., 26(16), 2481-2484, 1999.

Broström, A., M. Coe, S. P. Harrison, R. Gallimore, J. E. Kutzbach, J. Foley, I. C. Prentice, and P. Behling, Land surface feedbacks and palaeomonsoons in northern Africa, Geophys. Res. Lett., 25(19), 3615-3618, 1998.
Brovkin, V., M. Claussen, V. Petoukhov, and A. Ganopolski, On the stability of the atmosphere-vegetation system in the Sahara/Sahel region, J. Geophys. Res., 103(D24), 31,613-31,624, 1998.

Claussen, M., and V. Gayler, The greening of the Sahara during the midHolocene: Results of an interactive atmosphere-biome model, Global Ecol. Biogeogr. Lett., 6, 369-377, 1997.

Claussen, M., C. Kubatzki, V. Brovkin, and A. Ganopolski, Simulation of an abrupt change in Saharan vegetation in the mid-Holocene, Geophys. Res. Lett., 26(14), 2037-2040, 1999.

Coe, M. T., and G. B. Bonan, Feedbacks between climate and surface water in northern Africa during the middle Holocene, J. Geophys. Res., 102(D10), 11,087-11,101, 1997.

de Noblet-Ducoudré, N., M. Claussen, and C. Prentice, Mid-Holocene greening of the Sahara: First results of the GAIM 6000 year BP Experiment with two asynchronously coupled atmosphere/biome models, Clim. Dyn., 16, 643-659, 2000.

Doherty, R., J. Kutzbach, J. Foley, and D. Pollard, Fully coupled climate/ dynamical vegetation model simulations over northern Africa during the mid-Holocene, Clim. Dyn., 16, 561-573, 2000.

Eltahir, E. A. B., The role of vegetation in sustaining large-scale atmospheric circulations in the tropics, J. Geophys. Res., 101(D2), 42554268, 1996.

Eltahir, E. A. B., A soil moisture-rainfall feedback mechanism, 1, Theory and observations, Water Resour. Res., 34(4), 765-776, 1998.

Eltahir, E. A. B., and C. Gong, Dynamics of wet and dry years in West Africa, J. Clim., 9, 1030-1042, 1996.

Emanuel, K. A., J. D. Neelin, and C. S. Bretherton, On large scale circulations in convecting atmospheres, Q. J. R. Meteorol. Soc., 120, 1111$1143,1994$.

Foley, J. A., S. Levis, I. C. Prentice, D. Pollard, and S. L. Thompson, Coupling dynamic models of climate and vegetation, Global Change Biol., 4, 561-579, 1998.

Foley, J. A., I. C. Prentice, N. Ramankutty, S. Levis, D. Pollard, S. Sitch, and A. Haxeltine, An integrated biosphere model of land surface processes, terrestrial carbon balance, and vegetation dynamics, Global Biogeochem. Cycles, 10, 603-628, 1996.

Ganopolski, A., C. Kubatzki, M. Claussen, V. Brovkin, and V. Petoukhov, The influence of vegetation-atmosphere-ocean interaction on climate during the mid-Holocene, Science, 280, 1916-1919, 1998.

Gasse, F., and E. Van Campo, Abrupt post-glacial climate events in West Asia and North Africa monsoon domains, Earth Planet. Sci. Lett., 126, 435-456, 1994.

Gornitz, V., and NASA, A survey of anthropogenic vegetation changes in West Africa during the last century: Climatic implications, Clim. Change, 7, 285-325, 1995 .

Hall, N. M. J., and P. J. Valdes, A GCM simulation of the climate 6000 years ago, J. Clim., 10, 3-17, 1997.

Harrison, S. P., et al., Intercomparison of simulated global vegetation distributions in response to $6 \mathrm{kyr}$ BP orbital forcing, J. Clim., 11, 27212742, 1998.

Hoelzmann, P., D. Jolly, S.P. Harrison, F. Laarif, R. Bonnefille, and H-.J. Pachur, Mid-Holocene land-surface conditions in northern Africa and the Arabian peninsula: A dataset for the analysis of biogeophysical feedbacks in the climate system, Global Biogeochem. Cycles, 12(1), 35-51, 1998.

Jolly, D., et al., Biome reconstruction from pollen and plant macrofossil data for Africa and the Arabian Peninsula at 0 and 6000 years, J. Biogeogr., 25, 1007-1027, 1998a.

Jolly, D., S. P. Harrison, B. Damnati, and R. Bonnefille, Simulated climate and biomes of Africa during the Late Quaternary: Comparison with pollen and lake status data, Quat. Sci. Rev., 17, 629-657, 1998 b.

Kutzbach, J., G. Bonan, J. Foley, and S. P. Harrison, Vegetation and soil feedbacks on the response of the African monsoon to orbital forcing in the early to middle Holocene, Nature, 384(19/26), 623-626, 1996.

Kutzbach, J. E., and P. J. Guetter, The influence of changing orbital parameters and surface boundary conditions on climate simulations for the past 18000 years, J. Atmos. Sci., 43(16), 1726-1760, 1986.

Liu, Z., R. G. Gallimore, J. E. Kutzbach, W. Xu, Y. Golubev, P. Behling, and R. Selin, Modeling long-term climate changes with equilibrium asynchronous coupling, Clim. Dyn., 15, 325-340, 1999.

Masson, V., and S. Joussaume, Energetics of the 6000-yr BP atmospheric circulation in boreal summer, from large-scale to monsoon areas: A study with two versions of the LMD AGCM, J. Clim., 10, 2888-2903, 1997.

Otto-Bliesner, B. L., El Niño/La Niña and Sahel precipitation during the middle Holocene, Geophys. Res. Lett., 26(1), 87-90, 1999.

Prentice, I. C., W. Cramer, S. P. Harrison, R. Leemans, R. A. Monserud, and A. M. Solomon, A global biome model based on plant physiology and dominance, soil properties and climate, J. Biogeogr., 19, 117-134, 1992.

Ruddiman, W. F., and A. C. Mix, The North and Equatorial Atlantic at 9000 and 6000 yr B.P., in Global Climates Since the Last Glacial Maximum, 
edited by H. E. Wright, pp. 94-124, Univ. of Minn. Press, Minneapolis, 1993.

Smith, T. M., and R. W. Reynolds, A high resolution global sea surface temperature climatology for the 1961-90 base period, J. Clim., 11, 3320-3323, 1998.

Street-Perrott, F. A., and R. A. Perrott, Holocene vegetation, lake levels, and climate of Africa, in Global Climates Since the Last Glacial Maximum, edited by H. E. Wright, pp. 318-352, Univ. of Minn. Press, Minneapolis, 1993.

Texier, D., N. de Noblet, S. P. Harrison, A. Haxeltine, D. Jolly, S. Joussaume, F. Laarif, I. C. Prentice, and P. Tarasov, Quantifying the role of biosphere-atmosphere feedbacks in climate change: coupled model simulations for 6000 years BP and comparison with palaeodata for northern Eurasia and northern Africa, Clim. Dyn., 13, 865-882, 1997.

Wang, G., The role of vegetation dynamics in the climate of West Africa, Ph.D. thesis, Mass. Inst. of Technol., Cambridge, 2000.

Wang, G., and E. A. B. Eltahir, Biosphere-atmosphere interactions over West Africa, 1, Development and validation of a coupled dynamic model, Q. J. R. Meteorol. Soc., 126(565), 1239-1260, 2000a.

Wang, G., and E. A. B. Eltahir, Biosphere-atmosphere interactions over West Africa, 2, Multiple climate equilibria, Q. J. R. Meteorol. Soc., 126(565), 1261-1280, 2000b.
Wang, G., and E. A. B. Eltahir, Ecosystem dynamics and the Sahel drought, Geophys. Res. Lett., 27(6), 795-798, 2000c.

Wang, G., and E. A. B. Eltahir, Role of vegetation dynamics in enhancing the low-frequency variability of the Sahel rainfall, Water Resour. Res., 36(4), 1013-1022, 2000d.

Xue, Y., and J. Shukla, The influcene of land surface properties on Sahel climate, part I, Desertification, J. Clim., 6, 2232-2245, 1993.

Yu, G., and S. P. Harrison, An evaluation of the simulated water balance of Eurasia and northern Africa at 6000 y BP using lake status data, Clim. Dyn., 12, 723-735, 1996.

Zheng, X., and E. A. B. Eltahir, The role of vegetation in the dynamics of West African monsoons, J. Clim., 11, 2078-2096, 1998.

E. A. B. Eltahir, Ralph M. Parsons Laboratory, Massachusetts Institute of Technology, Cambridge, MA, USA. (eltahir@mit.edu)

M. M. Irizarry-Ortiz, 218 Wedgewood Circle, Greenacres, FL 33463, USA. (michelle@boriken.com)

G. Wang, Department of Civil and Environmental Engineering, University of Connecticut, Storrs, CT 06269, USA. (gwang@engr.uconn. edu) 

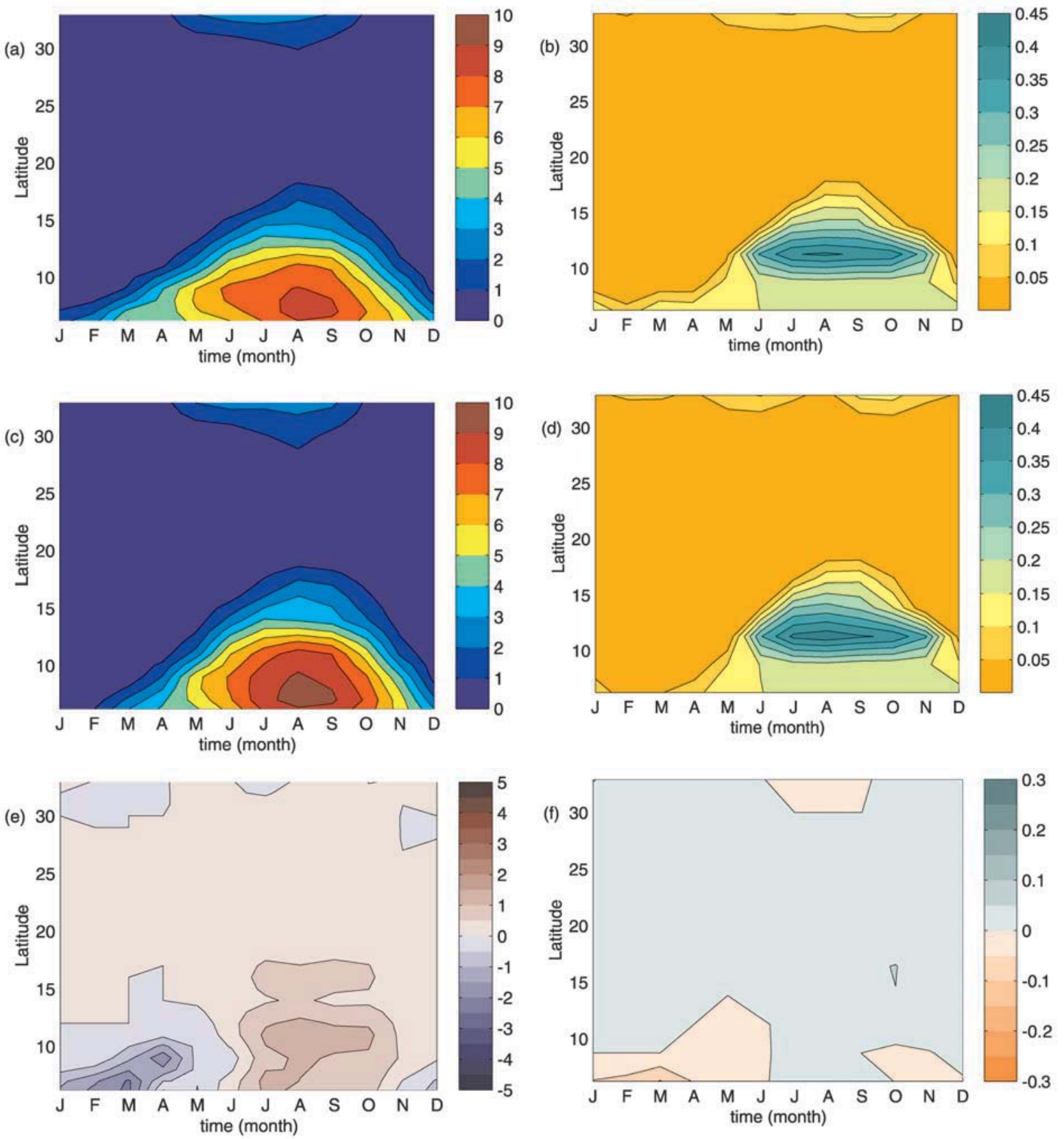

Figure 3. Results for simulations with vegetation fixed (static) to the current distribution (simulations VSC): (a) Seasonal cycle of rainfall (mm/day) and (b) net primary productivity $\left(\mathrm{kgC} / \mathrm{m}^{2} / \mathrm{mo}\right)$ for $0 \mathrm{~K}$ yrs $\mathrm{BP}$; (c) Seasonal cycle of rainfall and (d) net primary productivity for $6 \mathrm{~K}$ yrs BP; (e) Difference of Figures 3c and 3a; (f) Difference of Figures 3d and 3b. 

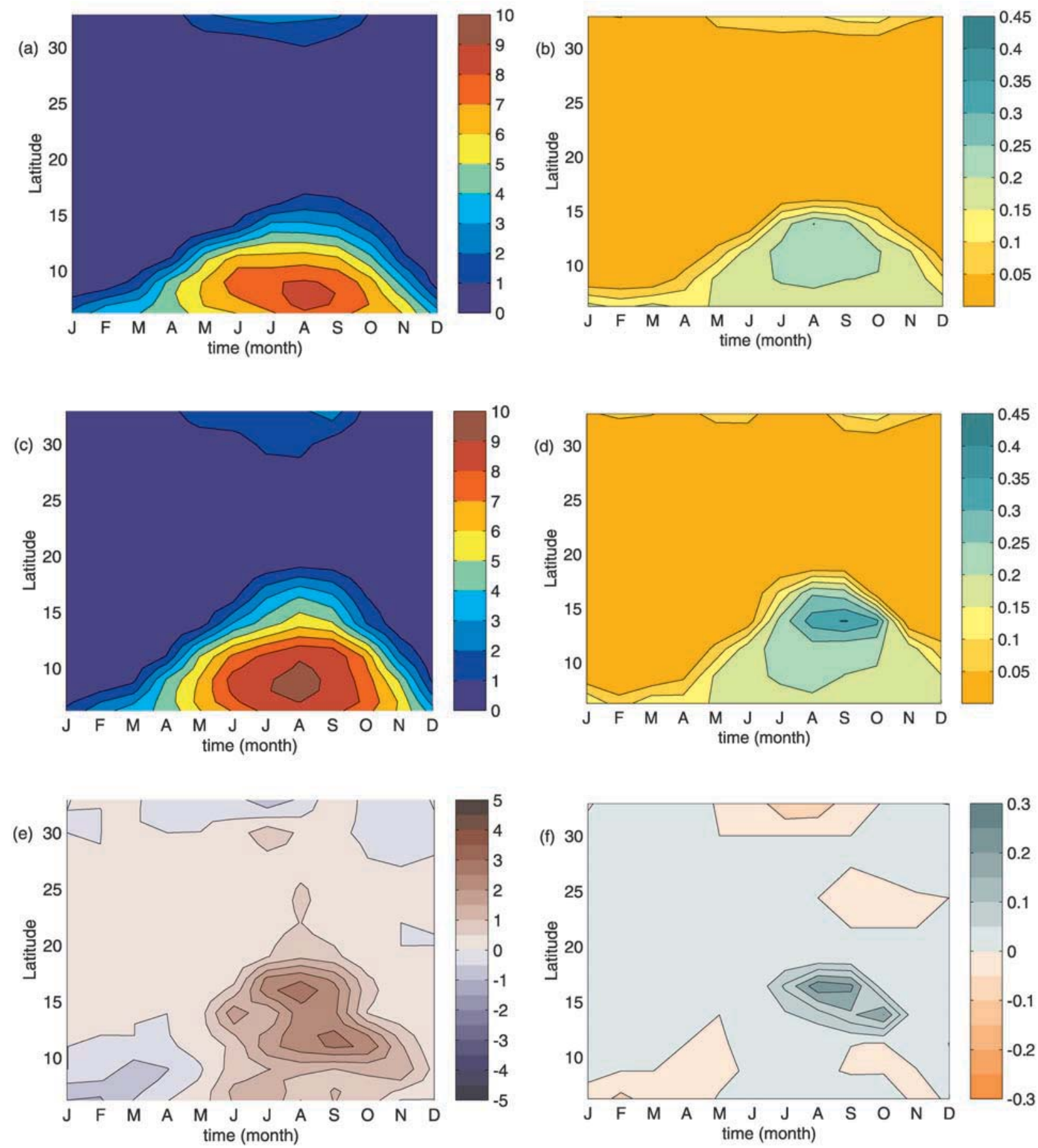

Figure 5. Results for simulations with vegetation initialized (dynamic) to the current distribution (simulations VDC): (a) Seasonal cycle of rainfall (mm/day) and (b) net primary productivity $\left(\mathrm{kgC} / \mathrm{m}^{2} /\right.$ mo) for $0 \mathrm{~K}$ yrs BP; (c) Seasonal cycle of rainfall and (d) net primary productivity for $6 \mathrm{~K}$ yrs BP; (e) Difference of Figures 5c and 5a; (f) Difference of Figures 5d and 5b. 

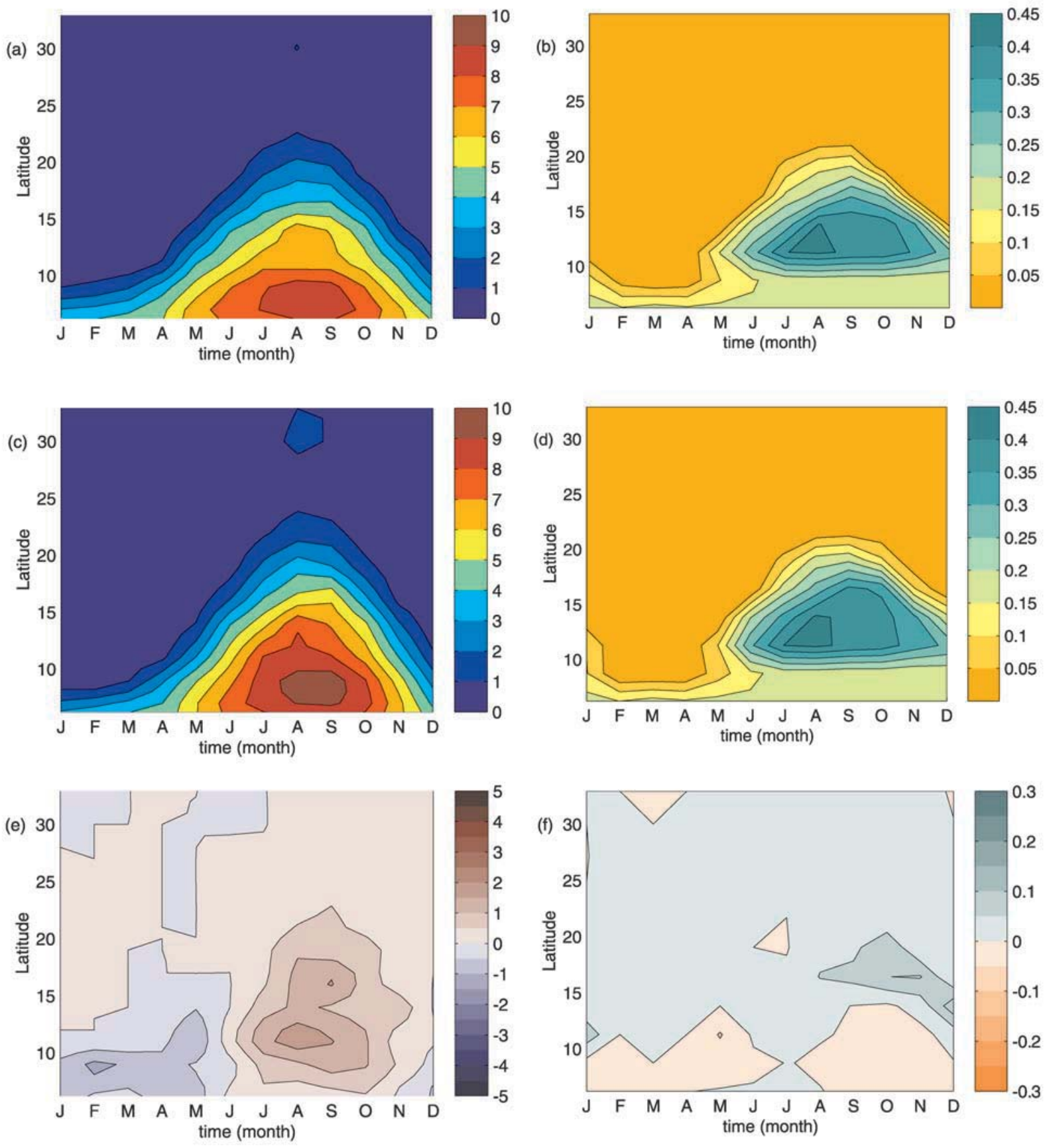

Figure 7. Results for simulations with vegetation fixed (static) to the Mid-Holocene distribution (simulations VSM): (a) Seasonal cycle of rainfall (mm/day) and (b) net primary productivity $\left(\mathrm{kgC} / \mathrm{m}^{2} /\right.$ mo) for $0 \mathrm{~K}$ yrs BP; (c) Seasonal cycle of rainfall and (d) net primary productivity for $6 \mathrm{~K}$ yrs BP; (e) Difference of Figures 7c and 7a; (f) Difference of Figures 7d and 7b. 

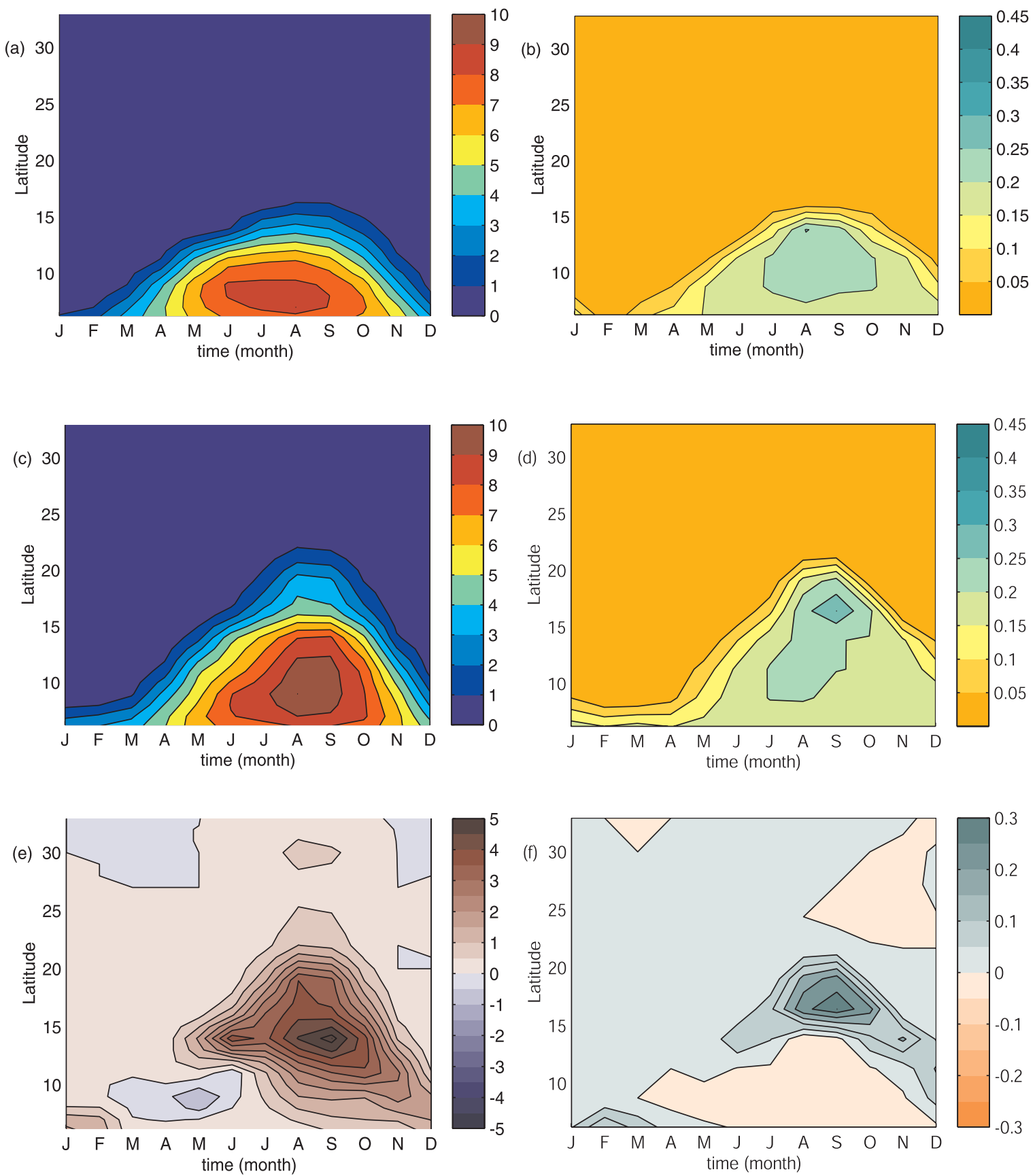

Figure 9. Results for simulations with vegetation initialized (dynamic) to the Mid-Holocene distribution (simulations VDM): (a) Seasonal cycle of rainfall ( $\mathrm{mm} /$ day) and (b) net primary productivity $\left(\mathrm{kgC} / \mathrm{m}^{2} / \mathrm{mo}\right)$ for $0 \mathrm{~K}$ yrs BP; (c) Seasonal cycle of rainfall and (d) net primary productivity for $6 \mathrm{~K}$ yrs BP; (e) Difference of Figures 9c and 9a; (f) Difference of Figures 9d and 9b. 